\title{
A review on applications of shape-stabilized phase change materials embedded in building enclosure in recent ten years
}

\begin{abstract}
Phase change material (PCM) elements in buildings as effective thermal energy storage technologies could decrease indoor temperature swings and lower building cooling/heating loads due to their great latent heat and proper thermal conductivity. Shape-stabilized phase change materials (SSPCMs) attracted interest of many researchers due to their outstanding ability of keeping shape for long-term multiple thermal cycles with no need of encapsulation. A summarize on thermal dynamic characteristic and thermal performance of buildings integrated with SSPCMs is important for us to gain a better understand on their performance and energy saving potential in both active and passive buildings. This study has reviewed applications of SSPCMs embedded in building enclosure in recent ten years (2008-2018). Both numerical and experimental research works on integrating SSPCMs into building envelope components, such as walls, floor, roof and windows, were reviewed, respectively. A thorough conclusion about this review work and appropriate recommendations for further studies were presented at the end of the paper. This review work will help both researchers and engineers to capture up-to-date uses of SSPCMs to achieve energy efficient buildings.
\end{abstract}

Keyword: shape-stabilized; phase change material; dynamic characteristic; thermal performance 


\section{Introduction}

Energy demand in building sectors has increased by around $30 \%$ of the total energy usage in the world [1]. It accounts for $41 \%$ of primary energy in the U.S.A. [2] and $40 \%$ of primary energy in the European Union [3]. Moreover, buildings are consuming more energy due to the population growth and people's requirement in better living environment [4]. Improving energy efficiency of buildings and using renewable energy technologies will help to reduce their energy usage, hence reducing global $\mathrm{CO}_{2}$ emissions.

Thermal energy storage, which can not only store thermal energy but also control temperature $[5,6]$ is a feasible choice of buildings to decrease their energy demand. Building envelope has a significant weighting in the building energy demands, so using PCMs in building envelope has been extensively studied in recent years to increase the buildings' thermal capacity and improve their thermal physical properties [7-9]. Proper utilization of PCMs will be able to lower building cooling/heating loads and shift peak loads. Moreover, PCMs can also help to remain a comfortable indoor thermal environment due to narrowed temperature swings. PCMs integrated into building envelopes can be classified as direct incorporation, immersion, encapsulation, shapestabilization and form stable composite PCMs [10].

Applying shape-stabilized PCMs (SSPCMs) in buildings has attracted interests of many researchers on account of their appropriate melting temperature, large latent heat capacity, proper thermal conductivity and ability of maintaining solid state for long- 
term multiple thermal cycles without encapsulation [11-13]. The incorporation of SSPCMs into building envelopes can increase building energy efficiency. SSPCMs can be organic, inorganic or eutectic. Supporting materials usable to prevent the flow of liquid PCMs are expanded graphite (EG), expanded perlite (EP), vermiculite, highdensity polyethylene, styrene, butadiene and so on. To enhance the thermal conductivity of PCM embedded building envelopes, additive materials such as EG, montmorillonite, pentaerythritol, melamine polyphosphate can be used. The PCMs, supporting materials and additive materials are melted and mixed fully together at high temperature, and the compound SSPCM is then cooled down and shaped in mold until it becomes solid. SSPCMs elements can be incorporate into contracture materials like walls, floor, roof and windows.

In this review, the classification of SSPCMs used in building envelope is presented in Section 2. Applications of SSPCMs in building walls, floor, roof and windows in recent ten years (2008-2018) are presented in Section 3. Section 4 involves appropriate discussions, conclusions and future work.

\section{Classification of SSPCMs in Building Envelope}

\subsection{Solid-liquid PCMs}

According to chemical compositions, solid-liquid PCMs used for building energy conservation can be classified as organic, inorganic and mixture solid-liquid PCMs, as shown in Error! Reference source not found.. Organic solid-liquid PCMs are generally chemically stable, with proper phase-transition temperature and large heat 
energy storage density, showing less or no supercooling. They can be divided into paraffin, fatty acids, polyethylene glycol and their eutectic mixture.

The thermal properties of some organic solid-liquid PCMs used in existing studies for buildings are listed Table 1, covering the past ten years.

Table 2 lists thermal properties of some inorganic solid-liquid PCMs. From the tables most solid-liquid PCMs used in buildings have phase-transition temperatures between $10^{\circ} \mathrm{C}$ and $30^{\circ} \mathrm{C}$ to provide thermally comfortably indoor environment for occupants.

\subsection{Microencapsulated PCMs}

Microencapsulation is a commonly used technique to avoid leakage of PCMs. It can decline the influence of ambient environment on the phase change behavior. It is an effective way of maintaining the configuration of PCMs during phase transition processes. Microencapsulated PCMs can be imbedded into building envelop to promote the thermal performance of buildings.

Microencapsulated PCMs are prepared by the process that SLPCMs are surrounded by a shell material or introduced in a matrix to provide small capsules with available behaviors. The preparation of microencapsulation can be divided into physical and chemical methods. The chemical method mainly includes interfacial, suspension, emulsion and in-situ polymerization [34-37]. The interfacial polymerization is realized by the process of high-rate polymerization reaction of hydrophilic monomers and 
lipophilic monomers at interphase of oil-in-water emulsion. It has advantages like high reaction rate, mild reaction course and low penetrability. Suspension polymerization is featured by immiscible particles stability exists in the continuous aqueous phase via agitating and stabilizers. Polymerization reaction initiates when the required temperature is reached. Emulsion polymerization is featured by the initiators and can be dissolved in water. Monomers can be emulsified by surfactant in polymerization medium. Poly (methyl methacrylate) (PMMA) is a common shell material used for producing microencapsulated PCMs (MEPCMs) by emulsion polymerization. In-situ polymerization is the most popular chemical method used to synthesis microencapsulated PCMs. Due to the inherent molecular structure of PCMs, the microencapsulation technique is mainly suitable for paraffin as core the material for microencapsulated PCMs [38]. A summary of microencapsulation PCMs prepared by the chemical method can be found in Table 3 .

\subsection{Form-stable composite PCMs}

Form-stable composite PCMs are fabricated by mixing PCMs with framework materials that are abundant in porous structure or 3D network structure. The framework material can restrict the flow of PCMs to prevent leakage. Commonly used framework materials include polymers (2.3.1) and inorganic porous (2.3.2) medias.

\subsubsection{Polymer-based form-stable composite PCMs}

The kind of composite PCMs can be fabricated by melting blending and casting molding methods. Polyethylene (PE) [45], polypropylene (PP) [46, 47], PMMA [4850], epoxy [51] and polyurethane (PU) [52-54], poly(vinyl chloride) (PVC) [55, 56] are 
commonly used framework materials.

In order to promote the energy conservation in buildings, Chen et al. [57] obtained a series of form-stable PCMs using paraffin as PCMs and three types of PE as supporting materials. In their study, the compatibility of paraffin with the three types of PE was studied. The results showed that high-density PE/paraffin had the weakest compatibility of the three combinations, based on which the authors suggested using HDPE/paraffin form-stable PCMs to reduce interior temperature fluctuations in buildings. Li et al. [58] used paraffin eutectic mixture as PCMs and PP as supporting materials to prepare paraffin/PP form-stable PCMs. The paraffin/PP form-stable composite PCMs had a high enthalpy of $126.8 \mathrm{~J} / \mathrm{g}$ with phase change temperature of $24.8^{\circ} \mathrm{C}$, so it can be used in building energy conservation with comfortable indoor environment. Wang et al. [59] used PMMA as supporting materials to synthesis formstable PCMs. The relationship between the content of LA-MA and combinational properties of composites were discussed. The optimum content of LA-MA was determined as 70\%. Tian et al. [60] prepared a kind of form-stable PCM with thermally conductivity by utilizing ethylene-vinyl acetate, paraffin, carbon fiber (CF) and EG. The Differential Scanning Calorimetry (DSC) results showed that the phase-transition temperature of FSPCM was $45.63^{\circ} \mathrm{C}$, with tested latent heat as $167.4 \mathrm{~J} / \mathrm{g}$. Kong et al. [53] studied the performance of PU/LA form-stable PCMs, and the results showed that PU/LA has superior thermal properties and can be used with solar energy for building applications.

The heat storage density of polymer-based form-stable composite PCMs is 
affected by the content of PCM. The mass fraction of PCM in the composite PCMs is higher the composite PCMs store a larger amount of latent heat. Moreover, polymers have good compatibility with the building materials. It is an effective way by using polymer as the framework to confine the leakage of PCM.

\subsubsection{Porous material-based form-stable composite PCMs}

Attributing to the absorption action, PCMs can be absorbed in the porous structure of porous materials to obtain form-stable PCMs using the vacuum impregnation method. EG, diatomite, montmorillonite, expanded perlite (EP), vermiculite [61, 62] are commonly used supporting materials due to their abundant pore structures.

EG shows a good compatibility with PCMs due to its large surface area and high surface activity [32, 63-66]. Yuan et al. [61, 75-77] used EG as framework materials and prepared a series of form-stable PCMs with different phase-transition temperatures. The content of fatty acids in the composites was up to 92.8 wt.\%. Diatomite has high absorptivity and porosity, but light weight, and Wen et al. [67] pointed out that diatomite is a viable candidate of light-weight and economical building materials for bringing PCMs into building energy efficiency. EP and vermiculite are a class of thermal insulation materials and are widely used in building applications. Zhang et al. [68] prepared PA-CNTs/EP form-stable PCMs with EP as supporting materials. The loading of PA in the form-stable PCMs is $62.52 \mathrm{wt} \%$. Zhang et al. [69] used vermiculite as framework materials and fatty acids eutectic mixture as PCMs to prepare form-stable PCMs, and their results reflected that the optimum weight ratio of PCMs in vermiculite was $50 \mathrm{wt} \%$ without seepage. 
The latent heat storage density of porous material-based form-stable PCMs is affected by the content of the PCMs absorbed in the framework materials. The structure of the pore material affects its absorption.

Table 4 lists the thermal properties of porous material-based form-stable PCMs that have been reported in existing literatures.

\section{Applications of SSPCMs in Building Envelope}

Building envelope is an important element affecting the heat exchange between interior and exterior environments. Indoor thermal environment changes with outdoor environment since the limited thermal capacity of conventional building envelope. Incorporating phase change materials into building elements can increase the thermal capacity of buildings, which makes the indoor thermal environment less sensitive to the outdoor environment. The building components that can incorporate PCMs are walls, floor, roof and windows, and the following session just reviews existing work concerning this aspect.

Common research methods in this direction could be classified as either experimental method or numerical method. Testing methods included differential scanning calorimetry, T-history, dynamic heat flow apparatus, dynamic hot box, dynamic guarded hot plate, M-value and so on. TRNSYS, EnergyPlus, DOE-2, COMSOL, Multiphysics, Matlab, ANASYS and CFD have been used in existing studies for building performance predictions/simulations.

3.1 Applications of SSPCMs in building walls 
A common method of using SSPCMs in building envelope is through building walls, on either internal or external surfaces or both [3]. SSPCMs can enhance the thermal capacity of lightweight structures significantly. Many experimental and numerical studies have demonstrated this effect and its impact on both indoor thermal environment and energy consumption.

\subsubsection{Experimental studies for building walls}

A specific kind of SSPCM bricks and their impact on the building performance has been evaluated by Li [82], for both mid-season (15th March 2016-15th May 2016) and summer (15th June 2016-19th June 2016, 4th July 2016-7th July 2016, 23rd July 2016-29th July 2016). Appearance of testing room was shown in Figure 2. In the study, the surface temperature and heat flux of both external and internal walls were monitored. The experiment results showed that the PCM walls were effective for the mid-season, but not for summer, and this was mainly due to the narrow and fixed melting temperature of PCMs. The applications of PCMs in real buildings should be optimized further. Another study was conducted in there seasons also including mid-season. Wang et al. [83] carried out an experiment in an actual PCM room, covering summer (12th August 2015-21st August 2015), autumn (13th October 2015-22nd October 2015) and winter (19th January 2016-4th January 2016). The SSPCM-mortar bricks consisted of portland cement (37.5\% in weight), yellow sand (22.5\% in weight) and SSPCMs $(40.0 \%$ in weight). With PCMs the room reduced $24.3 \%$ of cooling load and $10.0-30.0 \%$ heating load, respectively. The PCM wall was in solid state and could completely resist solar radiation from outside in autumn. So the two papers showed opposite conclusions 
about the performance of PCM in mid-season. It was because that the narrow melting temperature should be optimized by simulation before experiment in case of not taking phase change in experiment periods.

Kong et al. [84] studied the performance of buildings integrated with PCM panels under three operation measures in summer, between 24th August 2012 and 27th August 2012. The results measured from the testing rooms are shown in Figure 3. The experimental data demonstrated that PCM panels helped to decrease peak temperature, reduce temperature fluctuation and increase thermal inertia. Barreneche et al. [85] investigated both thermal and acoustical characteristics of SSPCM layers in a building between 4th June 2013 and 4th September 2013. In the measurement, the indoor air temperature was decreased by $3^{\circ} \mathrm{C}$ for the room with PCMs. In addition, the new SSPCM plate could insulate up to $4 \mathrm{~dB}$ noise compared with reference cubicles.

\subsubsection{Numerical studies for building walls}

The effect factors of PCMs on building performance were studied numerically. A one-dimensional mathematical model was developed by Izquierdo-Barrientos [86] for investigating the effect of PCMs in external walls. Several factors were studied in a common building envelope, including location, orientation, melting temperature of PCMs and weather conditions. The results showed that there was still no clear optimal melting temperature that can minimize the thermal load. It might vary from $5^{\circ} \mathrm{C}$ to $35^{\circ} \mathrm{C}$ for different seasons, wall orientations and locations of the PCM layer. The optimal location of a thin PCM layer wallboard was estimated numerically by Jin et al. [87, 88]. 
With the increase of thickness, heat fusion and melting temperature of PCMs, the PCM layer were recommended to be closer to the external side. While with the increase of internal surface temperature of the wall, the PCM layer was recommended to be closer to the internal side. Both occupancy and ventilation patterns may influence the energy saving potential of PCM buildings [89]. The effects of different PCM properties on the thermal performance of SSPCM wallboards in residential buildings have been simulated and analyzed in [90]. The results showed that exterior and interior PCM walls can reduce energy consumption by different methods, optimizing heat fusion, melting temperature and thermal conductivity. The best energy saving method of using PCMs in solar houses was attaching them onto internal walls.

The thermal and energy performance of PCM building under different operation methods or weather profiles were analyzed by simulations. Zhou et al. [91-93] investigated the thermal performance of an office building integrated with SSPCM wallboards under mechanical night ventilation in Beijing. The photos of the SSPCMs used were shown in Figure 4. The modeled data showed that with SSPCMs and night ventilation, the daily indoor thermal environment could be improved greatly with reduced cooling energy consumption by $76 \%$, compared with that without SSPCMs and night ventilation. Additionally, the thermal characteristic of SSPCM wallboards under sinusoidal heat flux waves were simulated numerically compared with conventional building materials [94]. Three factors were analyzed, including time lag, decrement factor and phase transition keeping time, and the results were useful when selecting SSPCMs for passive solar buildings. Lei et al. [95] studied the contribution of PCMs to 
reduce summer energy consumption in air-conditioned buildings in Singapore. The PCM layer was $10 \mathrm{~mm}$ with melting temperature of $28^{\circ} \mathrm{C}$ and was attached to the external surface of walls. The numerical data indicated that in a year PCMs could lower heat gains through walls for about $21-32 \%$, and this contribution was more obvious in tropics climate than other climatic regions. Auzeby et al. [96] have used Design Builder to demonstrate the effectiveness of PCMs on reducing summer overheating issues in UK residential buildings, with appropriate identifications of influential factors. From the simulation work, they proposed that PCMs can be a useful passive method to tackle the increasing summer temperature in the UK for residential buildings, most of which are naturally ventilated. Additionally, both environment and construction related factors would impact the PCM performance so the selection should be case-specific.

\subsubsection{Studies based on both experiment and numerical simulation for building walls}

Position and amount of PCM layer was important for building performance. Kim et al. [97, 98] proposed a SSPCM sheets to lower buildings' heating load in Japanese. A photo for the SSPCM sheet installation is shown in Figure 5. The effect of SSPCM sheets was tested in three types of huts: 1) no SSPCM sheet was embedded in Hut A; 2) four SSPCM sheets were embedded on the floor of Hut B, and 3) one SSPCM sheet was embedded on the floor, walls, and the roof of Hut C, respectively. The amount of SSPCMs was the same for Huts B and C. The study was conducted by both simulation and experiment. Compared with Hut A, the average energy saving effect of Hut $\mathrm{C}$ was better than Hut B. It meant that different installation area and position led to different thermal performances. The effect of position of PCM layer was also studied by Kong 
et al. [99]. They studied the thermal performance of buildings integrated with PCM walls and roof in summer. Two PCM systems and their thermal energy saving potentials were analyzed. PCMs installed outside and inside of the wall surface were named as PCMOW and PCMIW, respectively. Demonstrations of the two PCM panels are shown in Figure 6 and Figure 7, respectively, and PCMIW performed better than PCMOW, especially with nature ventilation.

Thermal and energy performance of PCM wall were investigated by many researchers. Meng et al. [100] proposed a room with different SSPCM wallboards placed on different orientations, which could active both in summer and winter. The appearances of both SP29 and RT18 are shown in Figure 8. The PCM model (Type 188) was developed in TRNSYS 17 and validated by experiment. Results indicated that the indoor air temperature fluctuations in the PCM room was reduced $4.3^{\circ} \mathrm{C}$ in summer and $14.2^{\circ} \mathrm{C}$ in winter, compared with the room without PCMs. A novel SSPCM wall was developed by Diaconu et al. [101], who evaluated its energy saving potential on both cooling and heating in a continental temperature climate. The external and internal wallboards worked in warm seasons and cold seasons, respectively. The melting temperature of external wallboards was higher than that of internal ones. The reduction for the total cooling load and heating load was $1.0 \%$ and $12.8 \%$, respectively. The reduction for the peak cooling load and heating load was $24.3 \%$ and $35.4 \%$, respectively. More factors could be considered and investigated to improve the performance of this novel SSPCM wall system in further study. Yao et al. [102] proposed a novel SSPCM wallboard made up of paraffin and expand perlite. A one-dimensional mathematical 
model for this SSPCM wallboard was developed on TRNSYS and validated by experimental data. The simulation result of the SSPCM wallboard incorporated in an office building indicated that the indoor air temperature was decreased by $9.22^{\circ} \mathrm{C}$ on average in summer.

The outdoor [103] and indoor environment [104] were influence factors on building performance. Ling et al. [103] justified the influence of PCMs on the thermal performance of solar greenhouses with varied climates for 61 days in the heating seasons. Schematic diagrams of the greenhouse were shown in Figure 9. The results indicated that the PCMs could improve indoor comfort in greenhouses during most of 61 days, especially in sunny days. Biswas et al. [104] studied the performance and energy-saving potential of nano-PCM wallboards in a real weather condition test facility located in Charleston with hot and humidity summer. The test wall with PCM wallboards is shown in Figure 10. Three types of set-points, i.e. $21^{\circ} \mathrm{C}, 22^{\circ} \mathrm{C}$ and $23.5^{\circ} \mathrm{C}$, were selected in the simulations to quantify the effect of nano-PCM wallboards on the room's energy performance. The simulation data indicated that the maximal cooling load reduction was reached at set point of $22^{\circ} \mathrm{C}$.

Model development of PCM element was important for simulation, but the study on this scope was scared. A one-dimensional phase change mathematical model (Type 272) was developed by TRNSYS and validated by experiment in a full size room [105]. The construction diagram and the completion diagram are shown in Figure 11. This simplified model can be used for both initial design and optimization of PCM rooms, and it is adaptable and reliable in different simulation conditions. 
The thermal performance of SSPCMs element embedded in building envelope under different operation methods and seasons was mainly investigated by simulations. Short-time experiments were not as comprehensive as long-time experiments. But experiments covering a whole winter season were scarce. Influential factors, such as location of PCM wallboards, orientation of PCM walls, properties of PCMs and ambient conditions, on the performance of PCM buildings were analyzed and optimized mainly in studies based on simulations. However most literatures were focusing on summer time, with limited discussions and investigations on winter time.

\subsection{Applications of SSPCMs in building floor}

PCM floor could store a large amount of latent heat due to direct absorption of solar energy in sunny days [3], hence with a considerable potential for energy saving.

\subsubsection{Experimental studies for building floor}

Karim et al. [106] put forward a novel SSPCM floor for thermal adjustment in lightweight buildings. Image of the floor panel is shown in Figure 12. Experiment results showed that such hollow concrete floor panels was suitable for lightweight office buildings, due to their ability of storing and shifting cooling load into the nighttime, hence improving indoor thermal environment during the daytime.

\subsubsection{Numerical studies for building floor}

A double-layer PCM floor has been put forward to store energy in the valley time and release energy in the peak time in winter/summer [107]. A schematic of the PCM floor is shown in Figure 13. Simulation results indicated that the energy released by the 
floor in peak time was promoted by $41.1 \%$, with optimal melting temperature of $38^{\circ} \mathrm{C}$ in winter. In summer, the energy released by the PCM floor in peak time was promoted by $37.9 \%$, with optimal melting temperature of $18^{\circ} \mathrm{C}$.

Using TRNSYS, Belmonte et al. [108] studied the application of radiant floor for releasing heat stored in PCMs. Simulation results indicated that with help from an airto-air heat recovery system this system could reduce more than $50 \%$ cooling energy consumption, comparing to the same building without PCMs. However, the predicted dissatisfied percent in the building with PCM floor increased by $2-5 \%$ than that without PCM floor.

3.2.3 Studies based on both experiment and numerical simulation for building floor

Influential factors of PCM floor on building performance were studied. A new PCM floor used in solar water heating system was proposed [109]. The process of constructing the novel PCM floor is shown in Figure 14. The thermal performance of PCM floor was measured under steady condition, and experimental results showed that solar water could provide $47.7 \%$ of energy. A heat transfer model was developed for numerical analysis. The numerical results showed that varying floor surface temperature was more easily affected by reducing hot water temperature than increasing it. Additionally, reducing thermal conductivity of decoration material was recommended for changing the floor surface temperature. Royon et al. [110] optimized on percentage of PCMs incorporated in a building floor. This PCM panel made use of an existing floor/ceiling board with cylindrical cavities. The cavities were lumped with 
polymer and paraffin. A numerical simulation was carried out on Comsol Multiphysics software and verified by experiment. The optimal percentage of PCM value was $50 \%$ in line with amplitude attenuation.

Performance of PCM floor was investigated by experiments and simulations. An experiments has been conducted to study the characteristics of a radiant floor heating system in a test room [111]. The thermal storage materials were sand and PCMs. The heat pipes were different and are shown in Figure 15. The experiment data during both charging and discharging periods were validated by simulation data using CFD software The study concluded that PCMs and capillary mat compound in low temperature floor were suitable for solar hot water heating system. Ye et al. [112] evaluated the performance of SSPCM floor in a full scale residential room using an energy saving index. Photos of the experiment unit are shown in Figure 16. The SSPCM panel was made up of paraffin as PCMs and graphite foam as supporting materials. The results showed that the SSPCM performed better in hot seasons and worse in cold seasons, while the insulation material had a better performance in a year.

Radiant floor heating system is one of the popular energy saving technologies for buildings. PCMs integrated into floor element could enhance its thermal storage and reduce temperature fluctuation. Therefore, using SSPCMs in building floor is a promising heating technology for buildings. However, its potential for cooling purpose is also needed of being investigated in the future. 


\subsection{Applications of SSPCMs in building roof}

Roof is important for building's indoor thermal comfort, since it can absorb solar radiation energy and heat energy from ambient environment. SSPCMs integrated into roof could narrow temperature variation of indoor air [3].

\subsubsection{Experimental studies for building roof}

Jaworski et al. [113] studied the thermal performance of PCM roof in an office building with night cooling strategy. A photo of the experimental platform is shown in Figure 17. Measured data indicated that not all PCMs in the panel charge/discharge energy since the PCM could active in a narrow temperature range. The optimization of this cooling system need to be further studied.

\subsubsection{Numerical studies for building roof}

Roman et al. [114] studied the influence of urban heat island on both cool roof and PCM roof in US cities, using EnergyPlus software. The study found that the maximal heat flux was $54 \%$ lower by the PCM roof than the cool roof, under wide range of albedo. At the same time, the maximal sensible heat flux for the PCM roof was reduced $40 \%$ than the cool roof under changing albedo.

Saffari et al. [115] has also investigated the effect of urban heat island on cool PCM roof. Rubitherm CSM PCM panel is shown in Figure 18. Optimization results showed that PCMs with higher melting point were suitable for reducing thermal stress in summer, while those with lower melting point were suitable for lower energy demand in winter. 
3.3.3 Studies based on both experiment and numerical simulation for building roof

Pasupathy et al. [116, 117] investigated thermal characteristic of double layer PCM roof in buildings in a year in India. A model was put forward and verified by experiment data. From the study a double layer PCM with different melting points $\left(27^{\circ} \mathrm{C}\right.$ and $\left.32^{\circ} \mathrm{C}\right)$ was recommended for reducing indoor temperature fluctuation in the year.

Application of SSPCMs in building roof has positive effects on urban heat island in summer. But the result is opposite in winter since PCMs would absorb heat from surrounding ambient. Therefore, using SSPCM roof is helpful for cooling-dominant areas but not for heating-dominant areas.

\subsection{Applications of SSPCMs in building windows}

Implementing SSPCMs into building windows has not attracted much research interests, and only a few studies have been carried out investigating the potential benefits of SSPCMs in window shuts. Additionally, no study has been found using both experiment and simulation methods. Windows are a high sector of energy demand in buildings. Excessive solar gain through glazed facades would lead to a high cooling demand in hot seasons. In cold seasons, windows are responsible for a large part of energy loss [3]. Therefore, it is very important to investigate whether PCMs can help to improve the performance of building windows.

\subsubsection{Experimental studies for windows}

Silva et al. $[118,119]$ put forward a window shutter with PCMs outside a full size experiment room, and a window blade filled with PCMs is shown in Figure 19. The 
window shutter was made of aluminum blades filled with paraffin RT28HC as PCMs. Experimental data showed that the maximum indoor air temperature with PCM shutter was $37.2^{\circ} \mathrm{C}, 16.6{ }^{\circ} \mathrm{C}$ lower than that without PCM shutter. The minimum indoor air temperature in both rooms were similar. The study justified that PCM window shutters could help to improve building's indoor thermal environment and energy efficiency.

\subsubsection{Numerical studies for windows}

A PCM incorporated window storing cold with night cooling and released it with forced ventilation by a fan has been developed for an office building [120]. The cooling unit configuration is shown in Figure 20. Paraffin was used as PCMs with optimal melting points between $22^{\circ} \mathrm{C}$ and $24^{\circ} \mathrm{C}$. Numerical data showed that indoor air temperature was lowered by $3.3^{\circ} \mathrm{C}$ within one hour using the PCM cooling unit and maintained the temperature for two hours from June 19th to 24th. The cooling system could save $1.9 \mathrm{kWh}$ in one hour than a conventional air conditioner with the same capacity.

The glazed areas and window shutters are important for reducing energy consumption of buildings. Using SSPCMs in building windows is an effective method of improving heat transfer through the glazed areas in summer. However, optimized methods considering thermal, indoor air quality (ventilation) and lighting are still highly required to combine PCMs with building windows.

\section{Outlook}

From the above literature work, it could be found that using PCMs could improve 
buildings' energy efficient while still keeping a comfortable environment, using either active or passive methods. In future studies, the following issues still need to be tackled.

4.1 Energy management of buildings with PCMs for a whole year

Existing applications of PCMs in buildings focused on specific seasons, e.g. summer (for cooling) or winter (for heating). For buildings requiring both cooling and heating, the use of PCMs is still very limited. Therefore, appropriate solutions on using PCMs for both heating and cooling applications (can be either for the whole year operation of a simple building or for operation of specific periods of a building with multi-zone conditions at the same time) are still highly required.

\subsection{Specific application methods in different buildings}

Different types of buildings, e.g. office buildings and residential buildings, may have significantly different requirements on thermal comfort, e.g. different temperature ranges. Therefore, how PCMs can adapt to these different requirements still need further investigations.

\subsection{Experiments in full scale PCM room and real weather climate}

Existing studies were carried out mainly in laboratories, which is much smaller than real buildings and also have controlled indoor environment. In real buildings, situations are much more complicated and more factors would impact the PCMs' performance. Therefore, critical testing of using PCMs in real buildings are highly required to better understand their actual performance and contributions. 
4.4 Combined PCM elements with other renewable energy technologies

PCMs have superiority on latent energy storage, but cannot be used as heat/cooling resources. Therefore, how to combine it with other renewable energy technologies as an important energy storage medium are essential for achieving energy efficient buildings.

\subsection{Flame resistant material as additive in PCM elements}

Combining flame resistant materials with PCMs is important for popularization and application in buildings, in order to increase the safety of the building. Though some flame resistant materials, such as EG, have been mentioned in existing literatures, more investigations on types and detailed properties are still needed.

\subsection{Combination of PCM elements in buildings}

The PCM elements have different functions of enhancing building thermal performance. Appropriate combinations of PCM walls, PCM floor, PCM roof and PCM windows in a building is a promising method for taking full advantage of latent heat materials in different buildings and climatic areas.

\section{Discussions and conclusions}

The classification and applications of SSPCMs embedded in building enclosure in recent ten years has been reviewed in this study. Inorganic porous materials and polymers have been popularly selected as supporting materials to prevent leakage of PCMs. Both experimental and numerical studies have been carried out to explore the 
use of SSPCMs in building walls, floor, roof and windows, like classified and summarized in Figure 21. Most existing studies (nearly $60 \%$ ) focused on walls, due to its big area in building envelope and main contribution to building thermal load. Studies on floor and roof were $19 \%$ and $13 \%$, respectively, with only $8 \%$ on windows.

SSPCMs are a promising technique to reduce the danger of leakage. Thermal dynamic characteristics and energy performance of SSPCM walls, floor, roof and windows have been investigated by many researchers. The SSPCM plaster enhanced building envelope can be effective in shifting peak cooling/heating load and/or reducing cooling/heating demand. From existing experimental and simulation works, it is clear that SSPCMs embedded in building enclosure could significantly narrow indoor temperature fluctuations and reduce energy demands. However further studies are still needed to be carried out about how to better incorporate SSPCM plaster into exiting building structures, its long-term stability and safety to human health and its reliability and practicability in real scale building under practical weather conditions.

\section{Acknowledgement}

This work presented in this paper is financially supported by grants of National Natural Science Foundation of China (No.51508212), Wuhan Youth Science and Technology Plan (No.2017050304010296) and The Central University Special Funding for Basic Scientific Research Business Expenses (No.2016YXZD071).

\section{References}

[1] Administration USEI, How much energy is consumed in the world by each sector? 
United States of America 2013.

[2] Energy USDO, Building energy data book, United States of America: Energy efficiency \& Renewable Energy 2011.

[3] S.E. Kalnas, B.P. Jelle, Phase change materials and products for building applications: A state-of-the-air review and future research opportunities, Energy and Buildings 94 (2015) 150-176.

[4] L. Perez-Lombard, J. Ortiz, C. Pout, A review on building energy consumption information, Energy and Building 40 (2008) 394-398.

[5] Y. Yuan, X. Cao, H. Wu, Z. Zhang, L. Sun, N. Yu, Coupled cooling method and application of latent heat thermal energy storage combined with pre-cooling of envelope: Method and model development, Energy 119 (2017) 817-833.

[6] X. Gao, Y. Yuan, X. Cao, H. Wu, X. Zhao, Coupled cooling method and application of latent heat thermal energy storage combining with pre-cooling of envelope: Sensitivity analysis and optimization, Process Safety and Environmental Protection 107 (2017) 438-445.

[7] R.K. Sharma, P. Ganesan, V.V. Tyagi, H.S.C. Metselaar, S.C. Sandaran, Developments in organic solid - liquid phase change materials and their applications in thermal energy storage, Energy Conversion and Management 95 (2015) 193-228.

[8] S. Nasser, A.L. Saadi, Z. Zhai, Modeling phase change materials embedded in building enclosure: A review, Renewable and Sustainable Energy Reviews 21 (2013) 
659-673.

[9] N. Soares, J.J. Costa, A.R. Gaspar, P. Santos, Review of passive PCM latent heat thermal energy storage systems towards buildings' energy efficiency, Energy and Buildings 59 (2013) 82-103.

[10] S.A. Memon, Phase change materials integrated in building walls: A state of the art review, Renewable and Sustainable Energy Review 31 (2014) 870-906.

[11] N. Zhu, S. Wang, X. Xu, Z. Ma, A simplified dynamic model of building structures integrated with shaped-stabilized phase change materials, International Journal of Thermal Sciences 49 (2010) 1722-1731.

[12] G. Zhou, Y. Yang, H. Xu, Energy performance of a hybrid space-cooling system in an office building using SSPCM thermal storage and night ventilation, Solar Energy 85 (2011) 477-485.

[13] N. Zhu, S. Wang, Z. Ma, Y. Sun, Energy performance and optimal control of air conditioned buildings with envelopes enhanced by phase change materials, Energy Conversion and Management 52 (2011) 3197-3205.

[14] M.I. Hasan, H.O. Basher, A.O. Shdhan, Experimental investigation of phase change materials for insulation of residential buildings, Sustainable Cities and Society $36(2018) 42-58$.

[15] R. Vicente, T. Silva, Brick masonry walls with PCM macrocapsules: An experimental approach, Applied Thermal Engineering 67 (2014) 24-34.

[16] M. Koschenz, B. Lehmann, Development of a thermally activated ceiling panel 
with PCM for application in lightweight and retrofitted buildings, Energy and Buildings $36(2004) 567-578$.

[17] X. Kong, P. Jie, C. Yao, Y. Liu, Experimental study on thermal performance of phase change material passive and active combined using for building application in winter, Applied Energy 206 (2017) 293-302.

[18] K. Kant, A. Shukla, A. Sharma, Heat transfer studies of building brick containing phase change materials, Solar Energy 155 (2017) 1233-1242.

[19] R. Luo, S. Wang, T. Wang, C. Zhu, T. Nomura, T. Akiyama, Fabrication of paraffin@SiO 2 shape-stabilized composite phase change material via chemical precipitation method for building energy conservation, Energy and Buildings 108 (2015) 373-380.

[20] Z. Chen, F. Shan, L. Cao, G. Fang, Preparation and thermal properties of noctadecane/molecular sieve composites as form-stable thermal energy storage materials for buildings, Energy and Buildings 49 (2012) 423-428.

[21] P. Saikia, A.S. Azad, D. Rakshit, Thermodynamic analysis of directionally influenced phase change material embedded building walls, International Journal of Thermal Sciences 126 (2018) 105-117.

[22] W. Kong, Z. Liu, Y. Yang, C. Zhou, J. Lei, Preparation and characterizations of asphalt/lauric acid blends phase change materials for potential building materials, Construction and Building Materials 152 (2017) 568-575.

[23] F. Tang, L. Cao, G. Fang, Preparation and thermal properties of stearic acid/titanium dioxide composites as shape-stabilized phase change materials for 
building thermal energy storage, Energy and Buildings 80 (2014) 352-357.

[24] R. Wen, X. Zhang, Y. Huang, Z. Yin, Z. Huang, M. Fang, Y.G. Liu, X. Wu, Preparation and properties of fatty acid eutectics/expanded perlite and expanded vermiculite shape-stabilized materials for thermal energy storage in buildings, Energy and Buildings 139 (2017) 197-204.

[25] C. Liu, Y. Yuan, N. Zhang, X. Cao, X. Yang, A novel PCM of lauric-myristicstearic acid/expanded graphite composite for thermal energy storage, Materials Letters $120(2014) 43-46$.

[26] N. Zhang, Y. Yuan, Y. Yuan, T. Li, X. Cao, Lauric-palmitic-stearic acid/expanded perlite composite as form-stable phase change material: Preparation and thermal properties, Energy and Buildings 82 (2014) 505-511.

[27] Y. Yang, Y. Pang, Y. Liu, H. Guo, Preparation and thermal properties of polyethylene glycol/expanded graphite as novel form-stable phase change material for indoor energy saving, Materials Letters (2018).

[28] Y. Deng, J. Li, T. Qian, W. Guan, Y. Li, X. Yin, Thermal conductivity enhancement of polyethylene glycol/expanded vermiculite shape-stabilized composite phase change materials with silver nanowire for thermal energy storage, Chemical Engineering Journal 295 (2016) 427-435.

[29] A.C. Evers, M.A. Medina, Y. Fang, Evaluation of the thermal performance of frame walls enhanced with paraffin and hydrated salt phase change materials using a dynamic wall simulator, Building and Environment 45 (2010) 1762-1768.

[30] F. Berroug, E.K. Lakhal, M.E. Omari, M. Faraji, H.E. Qarnia, Thermal 
performance of a greenhouse with a phase change material north wall, Energy and Buildings 43 (2011) 3027-3035.

[31] X. Jin, S. Zhang, X. Xu, X. Zhang, Effects of PCM state on its phase change performance and the thermal performance of building walls, Building and Environment 81 (2014) 334-339.

[32] Y. Wu, T. Wang, Hydrated salts/expanded graphite composite with high thermal conductivity as a shape-stabilized phase change material for thermal energy storage, Energy Conversion and Management 101 (2015) 164-171.

[33] Y. Liu, M. Xie, X. Gao, Y. Yang, Y. Sang, Experimental exploration of incorporating form-stable hydrate salt phase change materials into cement mortar for thermal energy storage, Applied Thermal Engineering 140 (2018) 112-119.

[34] J.F. Su, L.X. Wang, L. Ren, Z. Huang, X.W. Meng, Preparation and characterization of polyurethane microcapsules containing $\mathrm{n}$ - octadecane with styrene - maleic anhydride as a surfactant by interfacial polycondensation, Journal of Applied Polymer Science 102 (2010) 4996-5006.

[35] L. Sánchez, P. Sánchez, M. Carmona, A.D. Lucas, J.F. Rodríguez, Influence of operation conditions on the microencapsulation of PCMs by means of suspension-like polymerization, Colloid and Polymer Science 286 (2008) 1019-1027.

[36] D. Yin, M. Li, J. Liu, Q. Zhang, Pickering emulsion: A novel template for microencapsulated phase change materials with polymer-silica hybrid shell, Energy 64 (2014) 575-581.

[37] W. Su, J. Darkwa, G. Kokogiannakis, Development of microencapsulated phase 
change material for solar thermal energy storage, Applied Thermal Engineering 112 (2017) 1205-1212.

[38] Y. Konuklu, M. Ostry, H.O. Paksoy, P. Charvat, Review on using microencapsulated phase change materials (PCM) in building applications, Energy and Buildings 106 (2015) 134-155.

[39] K. Tumirah, M.Z. Hussein, Z. Zulkarnain, R. Rafeadah, Nano-encapsulated organic phase change material based on copolymer nanocomposites for thermal energy storage, Energy 66 (2014) 881-890.

[40] F. Irani, Z. Ranjbar, S. Moradian, A. Jannesari, Microencapsulation of $n$ heptadecane phase change material with starch shell, Progress in Organic Coatings 113 (2017) 31-38.

[41] F. Tang, L. Liu, G. Alva, Y. Jia, G. Fang, Synthesis and properties of microencapsulated octadecane with silica shell as shape-stabilized thermal energy storage materials, Solar Energy Materials and Solar Cells 160 (2017) 1-6.

[42] Z. Chen, M. Qin, J. Yang, Synthesis and characteristics of hygroscopic phase change material: Composite microencapsulated phase change material (MPCM) and diatomite, Energy and Buildings 106 (2015) 175-182.

[43] C. Alkan, A. Sarı, A. Karaipekli, Preparation, thermal properties and thermal reliability of microencapsulated n-eicosane as novel phase change material for thermal energy storage, Energy Conversion and Management 52 (2011) 687-692.

[44] S. Zhan, S. Chen, L. Chen, W. Hou, Preparation and characterization of polyurea microencapsulated phase change material by interfacial polycondensation method, 
Powder Technology 292 (2016) 217-222.

[45] P. Sobolciak, M. Karkri, M.A. Al-Maadeed, I. Krupa, Thermal characterization of phase change materials based on linear low-density polyethylene, paraffin wax and expanded graphite, Renewable Energy 88 (2016) 372-382.

[46] M.J. Mochane, A.S. Luyt, Preparation and properties of polystyrene encapsulated paraffin wax as possible phase change material in a polypropylene matrix, Thermochimica Acta 544 (2012) 63-70.

[47] C. Alkan, K. Kaya, A. Sarı, Preparation, Thermal Properties and Thermal Reliability of Form-Stable Paraffin/Polypropylene Composite for Thermal Energy Storage, Journal of Polymers and the Environment 17 (2009) 254.

[48] L. Zhang, J. Zhu, W. Zhou, J. Wang, Y. Wang, Thermal and electrical conductivity enhancement of graphite nanoplatelets on form-stable polyethylene glycol/polymethyl methacrylate composite phase change materials, Energy 39 (2012) 294-302.

[49] C. Alkan, A. Sari, Fatty acid/poly(methyl methacrylate) (PMMA) blends as formstable phase change materials for latent heat thermal energy storage, Solar Energy 82 (2008) 118-124.

[50] A. Sarı, C. Alkan, A. Karaipekli, O. Uzun, Poly(ethylene glycol)/poly(methyl methacrylate) blends as novel form - stable phase - change materials for thermal energy storage, Journal of Applied Polymer Science 116 (2010) 929-933.

[51] Z. Wang, W. Situ, X. Li, G. Zhang, Z. Huang, W. Yuan, C. Yang, C. Yang, Novel shape stabilized phase change material based on epoxy matrix with ultrahigh cycle life for thermal energy storage, Applied Thermal Engineering 123 (2017) 1006-1012. 
[52] B. Tang, L. Wang, Y. Xu, J. Xiu, S. Zhang, Hexadecanol/phase change polyurethane composite as form-stable phase change material for thermal energy storage, Solar Energy Materials and Solar Cells 144 (2016) 1-6.

[53] W. Kong, X. Fu, Y. Yuan, Z. Liu, J. Lei, Preparation and thermal properties of crosslinked polyurethane/lauric acid composites as novel form stable phase change materials with a low degree of supercooling, Rsc Advances 7 (2017) 29554-29562.

[54] K. Chen, X. Yu, C. Tian, J. Wang, Preparation and characterization of form-stable paraffin/polyurethane composites as phase change materials for thermal energy storage, Energy Conversion and Management 77 (2014) 13-21.

[55] A. Sari, K. Kaygusuz, Studies on poly(vinyl chloride)/fatty acid blends as shapestabilized phase change material for latent heat thermal energy storage, Indian Journal of Engineering \& Materials Sciences 13 (2006) 253-258.

[56] X. Jin, J. Li, P. Xue, M. Jia, Preparation and characterization of PVC-based formstable phase change materials, Solar Energy Materials and Solar Cells 130 (2014) 435441.

[57] F. Chen, M.P. Wolcott, Miscibility studies of paraffin/polyethylene blends as formstable phase change materials, European Polymer Journal 52 (2014) 44-52.

[58] L. Li, G. Wang, C. Guo, Influence of intumescent flame retardant on thermal and flame retardancy of eutectic mixed paraffin/polypropylene form-stable phase change materials, Applied Energy 162 (2016) 428-434.

[59] L. Wang, D. Meng, Fatty acid eutectic/polymethyl methacrylate composite as form-stable phase change material for thermal energy storage, Applied Energy 87 (2010) 
2660-2665.

[60] B. Tian, W. Yang, L. Luo, J. Wang, K. Zhang, J. Fan, J. Wu, T. Xing, Synergistic enhancement of thermal conductivity for expanded graphite and carbon fiber in paraffin/EVA form-stable phase change materials, Solar Energy 127 (2016) 48-55.

[61] Z.J. Duan, H.Z. Zhang, L.X. Sun, Z. Cao, F. Xu, Y.J. Zou, H.L. Chu, S.J. Qiu, C.L. Xiang, H.Y. Zhou, $\mathrm{CaCl} 2 \cdot 6 \mathrm{H} 2 \mathrm{O} /$ Expanded graphite composite as form-stable phase change materials for thermal energy storage, Journal of Thermal Analysis and Calorimetry 115 (2014) 111-117.

[62] P. Lv, C. Liu, Z. Rao, Review on clay mineral-based form-stable phase change materials: Preparation, characterization and applications, Renewable \& Sustainable Energy Reviews 68 (2017) 707-726.

[63] A. Celzard, S. Schneider, J.F. Marêché, Densification of expanded graphite, Carbon 40 (2002) 2185-2191.

[64] A. Celzard, J.F. Marêché, G. Furdin, Surface area of compressed expanded graphite, Carbon 40 (2002) 2713-2718.

[65] Y. Yuan, Y. Yuan, N. Zhang, Y. Du, X. Cao, Preparation and thermal characterization of capric-myristic-palmitic acid/expanded graphite composite as phase change material for energy storage, Materials Letters 125 (2014) 154-157.

[66] Z. Zhang, X. Fang, Study on paraffin/expanded graphite composite phase change thermal energy storage material, Energy Conversion and Management 47 (2005) 303310.

[67] R. Wen, X. Zhang, Z. Huang, M. Fang, Y. Liu, X. Wu, X. Min, W. Gao, S. Huang, 
Preparation and thermal properties of fatty acid/diatomite form-stable composite phase change material for thermal energy storage, Solar Energy Materials and Solar Cells 178 (2018) 273-279.

[68] X. Zhang, R. Wen, Z. Huang, C. Tang, Y. Huang, Y. Liu, M. Fang, X. Wu, X. Min, Y. Xu, Enhancement of thermal conductivity by the introduction of carbon nanotubes as a filler in paraffin/expanded perlite form-stable phase-change materials, Energy and Buildings 149 (2017) 463-470.

[69] N. Zhang, Y. Yuan, T. Li, X. Cao, X. Yang, Study on thermal property of lauricpalmitic-stearic acid/vermiculite composite as form-stable phase change material for energy storage, Advances in Mechanical Engineering 7 (2015) 1-8.

[70] Z. Zhang, X. Fang, Study on paraffin/expanded graphite composite phase change thermal energy storage material, Energy Conversion and Management 47 (2006) 303310.

[71] X. Yang, Y. Yuan, N. Zhang, X. Cao, C. Liu, Preparation and properties of myristic-palmitic-stearic acid/expanded graphite composites as phase change materials for energy storage, Solar Energy 99 (2014) 259-266.

[72] N. Zhang, Y. Yuan, Y. Du, X. Cao, Y. Yuan, Preparation and properties of palmiticstearic acid eutectic mixture/expanded graphite composite as phase change material for energy storage, Energy 78 (2014) 950-956.

[73] X. Tang, B. Zhu, M. Xu, W. Zhang, Z. Yang, Y. Zhang, G. Yin, D. He, H. Wei, X. Zhai, Shape-stabilized phase change materials based on fatty acid eutectics/expanded graphite composites for thermal storage, Energy and Buildings 109 (2015) 353-360. 
[74] J.-L. Zeng, J. Gan, F.-R. Zhu, S.-B. Yu, Z.-L. Xiao, W.-P. Yan, L. Zhu, Z.-Q. Liu, L.-X. Sun, Z. Cao, Tetradecanol/expanded graphite composite form-stable phase change material for thermal energy storage, Solar Energy Materials and Solar Cells 127 (2014) 122-128.

[75] D. Kim, J. Jung, Y. Kim, M. Lee, J. Seo, S.B. Khan, Structure and thermal properties of octadecane/expanded graphite composites as shape-stabilized phase change materials, International Journal of Heat and Mass Transfer 95 (2016) 735-741. [76] Y. Wu, T. Wang, Hydrated salts/expanded graphite composite with high thermal conductivity as a shape-stabilized phase change material for thermal energy storage, Energy Conversion and Management 101 (2015) 164-171.

[77] R. Ye, W. Lin, K. Yuan, X. Fang, Z. Zhang, Experimental and numerical investigations on the thermal performance of building plane containing $\mathrm{CaCl} 2 \cdot 6 \mathrm{H} 2 \mathrm{O} /$ expanded graphite composite phase change material, Applied Energy 193 (2017) 325-335.

[78] Y. Konuklu, O. Ersoy, O. Gokce, Easy and industrially applicable impregnation process for preparation of diatomite-based phase change material nanocomposites for thermal energy storage, Applied Thermal Engineering 91 (2015) 759-766.

[79] A. Sar1, A. Karaipekli, Preparation, thermal properties and thermal reliability of capric acid/expanded perlite composite for thermal energy storage, Materials Chemistry and Physics 109 (2008) 459-464.

[80] A. Sarı, A. Karaipekli, C. Alkan, Preparation, characterization and thermal properties of lauric acid/expanded perlite as novel form-stable composite phase change 
material, Chemical Engineering Journal 155 (2009) 899-904.

[81] R. Wen, Z. Huang, Y. Huang, X. Zhang, X. Min, M. Fang, Y.g. Liu, X. Wu, Synthesis and characterization of lauric acid/expanded vermiculite as form-stabilized thermal energy storage materials, Energy and Buildings 116 (2016) 677-683.

[82] L. Li, H. Yu, R. Liu, Research on composite-phase change materials (PCMs)-bricks in the west wall of room-scale cubicle: Mid-season and summer day cases, Building and Environment 123 (2017) 494-503.

[83] X. Wang, H. Yu, L. Li, M. Zhao, Experimental assessment on the use of phase change materials (PCMs)-bricks in the exterior wall of a full-scale room, Energy Conversion and Management 120 (2016) 81-89.

[84] X. Kong, S. Lu, J. Huang, Z. Cai, S. Wei, Experimental research on the use of phase change materials in perforated brick rooms for cooling storage, Energy and Buildings 62 (2013) 597-604.

[85] C. Barreneche, L. Navarro, A. Gracia, A.I. Fernandez, In situ thermal and acoustic performance and environmental impact of the introduction of a shape-stabilized PCM layer for building, Renewable Energy 85 (2016) 281-286.

[86] M.A. Izquierdo-Barrientos, J.F. Belmonte, D. Rodriguez-Sanchez, A.E. Molina, J.A. Almendros-Ibanez, A numerical study of external building walls containing phase change materials (PCM), Applied Thermal Engineering 47 (2012) 73-85.

[87] X. Jin, M.A. Medina, X. Zhang, Numerical analysis for the optimal location of a thin PCM layer in frame walls, Applied Thermal Engineering 103 (2016) 1057-1063. 
[88] X. Jin, M.A. Medina, X. Zhang, On the importance of the location of PCMs in building walls for enhanced thermal performance, Applied Energy 106 (2013) 72-78.

[89] B.M. Diaconu, Thermal energy savings in buildings with PCM-enhanced envelope: Influence of occupancy pattern and ventilation, Energy and Buildings 43 (2011) 101107.

[90] Y. Zhang, K. Lin, Y. Jiang, G. Zhou, Thermal storage and nonlinear heat-transfer characteristics of PCM wallboard, Energy and Buildings 40 (2008) 1771-1779.

[91] G. Zhou, Y. Yang, H. Xu, Energy performance of a hybrid space-cooling system in an office building using SSPCM thermal storage and night ventilation, Solar Energy 85 (2011) 477-485

[92] G. Zhou, Y. Yang, X. Wang, S. Zhou, Numerical analysis of effect of shapestabilized phase change material plates in a building combined with night ventilation, Applied Energy 86 (2009) 52-59.

[93] G. Zhou, Y. Zhang, K. Lin, W. Xiao, Thermal analysis of a direct-gain room with shape-stabilized PCM plates, Renewable Energy 33 (2018) 1228-1236.

[94] G. Zhou, Y. Yang, H. Xu, Performance of shape-stabilized phase change material wallboard with periodical outside heat flux waves, Applied Energy 88 (2011) 21132121.

[95] J. Lei, J. Yang, E. Yang, Energy performance of building envelopes integrated with phase change materials for cooling load reduction in tropical Singapore, Applied 
Energy 162 (2016) 207-217.

[96] M. Auzeby., S. Wei, C. Underwood, J. Tindall, C. Chen, H. Ling, R. Buswell, Effectiveness of Using Phase Change Materials on Reducing Summer Overheating Issues in UK Residential Buildings with Identification of Influential Factors, Energies $9(2016) 605$.

[97] H.B. Kim, M. Mae, Y. Choi, Application of shape-stabilized phase-change material sheets as thermal energy storage to reduce heating load in Japanese climate, Building and Environment 125 (2017) 1-14.

[98] H.B. Kim, M. Mae, Y. Choi, T. Kiyota, Experimental analysis of thermal performance in buildings with shape-stabilized phase change materials, Energy and Buildings 152 (2017) 524-533.

[99] X. Kong, S. Lu, Y. Li, J. Huang, S. Liu, Numerical study on the thermal performance of building wall and roof incorporating phase change material panel for passive cooling application, Energy and Buildings 81 (2014) 404-415.

[100] E. Meng, H. Yu, G. Zhan, Y. He, Experimental and numerical study of the thermal performance of a new type of phase change material room, Energy Conversion and Management 74 (2013) 386-394.

[101] B.M. Diaconu, M. Cruceru, Novel concept of composite phase change material wall system for year-round thermal energy savings, Energy and Buildings 42 (2010) 1759-1772. 
[102] C. Yao, X. Kong, Y. Li, Y. Du, C. Qi, Numerical and experimental research of cold storage for a novel expanded perlite-based shape-stabilized phase change material wallboard used in building, Energy Conversion and Management 155 (2018) 20-31.

[103] H. Ling, C. Chen, S. Wei, Y. Guan, C. Ma, G. Xie, N. Li, Z. Chen, Effect of phase change materials on indoor thermal environment under different weather conditions and over a long time, Applied Energy 140 (2015) 329-337.

[104] K. Biswas, J. Lu, P. Soroushian, S. Shrestha, Combined experimental and numerical evaluation of a prototype nano-PCM enhanced wallboard, Applied Energy

[105] S. Lu, S. Liu, J. Huang, X. Kong, Establishment and experimental verification of PCM room's TRNSYS heat transfer model based on latent heat utilization ratio, Energy and Buildings 84 (2014) 287-298.

[106] L. Karim, F. Barbeon, P. Gegout, A. Bontemps, L. Royon, New phase-change material components for thermal management of the light weight envelope of buildings, Energy and Buildings 68 (2014) 703-706.

[107] X. Jin, X. Zhang, Thermal analysis of a double layer phase change material floor, Applied Thermal Engineering 31 (2011) 1576-1581.

[108] J.F. Belmonte, P. Eguia, A.E. Molina, J.A. Almendros-Ibanez, Thermal simulation and system optimization of a chilled ceiling coupled with a floor containing a phase change material (PCM), Sustainable Cities and Society 14 (2015) 154-170.

[109] K. Huang, G. Feng, J. Zhang, Experimental and numerical study on phase change 
material floor in solar water heating system with a new design, Solar Energy 105 (2014) $126-138$.

[110] L. Royon, L. Karim, A. Bontemps, Optimization of PCM embedded in a floor panel developed for thermal management of the lightweight envelope of buildings, Energy and Buildings 82 (2014) 385-390.

[111] G. Zhou, J. He, Thermal performance of a radiant floor heating system with different heat storage materials and heating pipes, Applied Energy 138 (2015) 648-660.

[112] H. Ye, L. Long, H. Zhang, R. Zou, The performance evaluation of shapestabilized phase change materials in building applications using energy saving index, Applied Energy 113 (2014) 1118-1126.

[113] M. Jaworski, Thermal performance of building element containing phase change material (PCM) integrated with ventilation system - An experimental study, Applied Thermal Engineering 70 (2014) 665-674.

[114] K.K. Roman, T. O’Brien, J.B. Alvey, O. Woo, Simulating the effects of cool roof and PCM (phase change materials) based roof to mitigate UHI (urban heat island) in prominent US cites, Energy 96 (2016) 103-117.

[115] M. Saffari, C. Piselli, A. Gracia, A.L. Pisello, F. Cotana, L.F. Cabeza, Thermal stress reduction in cool roof membranes using phase change materials (PCM), Energy and Buildings 158 (2018) 1097-1105.

[116] A. Pasupathy, R. Velraj, Effect of double layer phase change material in building 
roof for year round thermal management, Energy and Buildings 40 (2008) 191-203.

[117] A. Pasupathy, L. Athanasius, R. Velraj, R.V. Seeniraj, Experimental investigation and numerical simulation analysis on the thermal performance of a building roof incorporating phase change material (PCM) for thermal management, Applied Thermal Engineering 28 (2008) 556-565.

[118] T. Silva, R. Vicente, F. Rodrigues, A. Samagaio, C. Cardoso, Development of a window shutter with phase change materials: Full scale outdoor experimental approach, Energy and Buildings 88 (2015) 110-121.

[119] T. Silva, R. Vicente, F. Rodrigues, A. Samagaio, C. Cardoso, Performance of a window shutter with phase change material under summer Mediterranean climate conditions, Applied Thermal Engineering 84 (2015) 246-256.

[120] Y. Xiang, G. Zhou, Thermal performance of a window-based cooling unit phase change materials combined with night ventilation, Energy and Buildings 108 (2015) 267-278. 


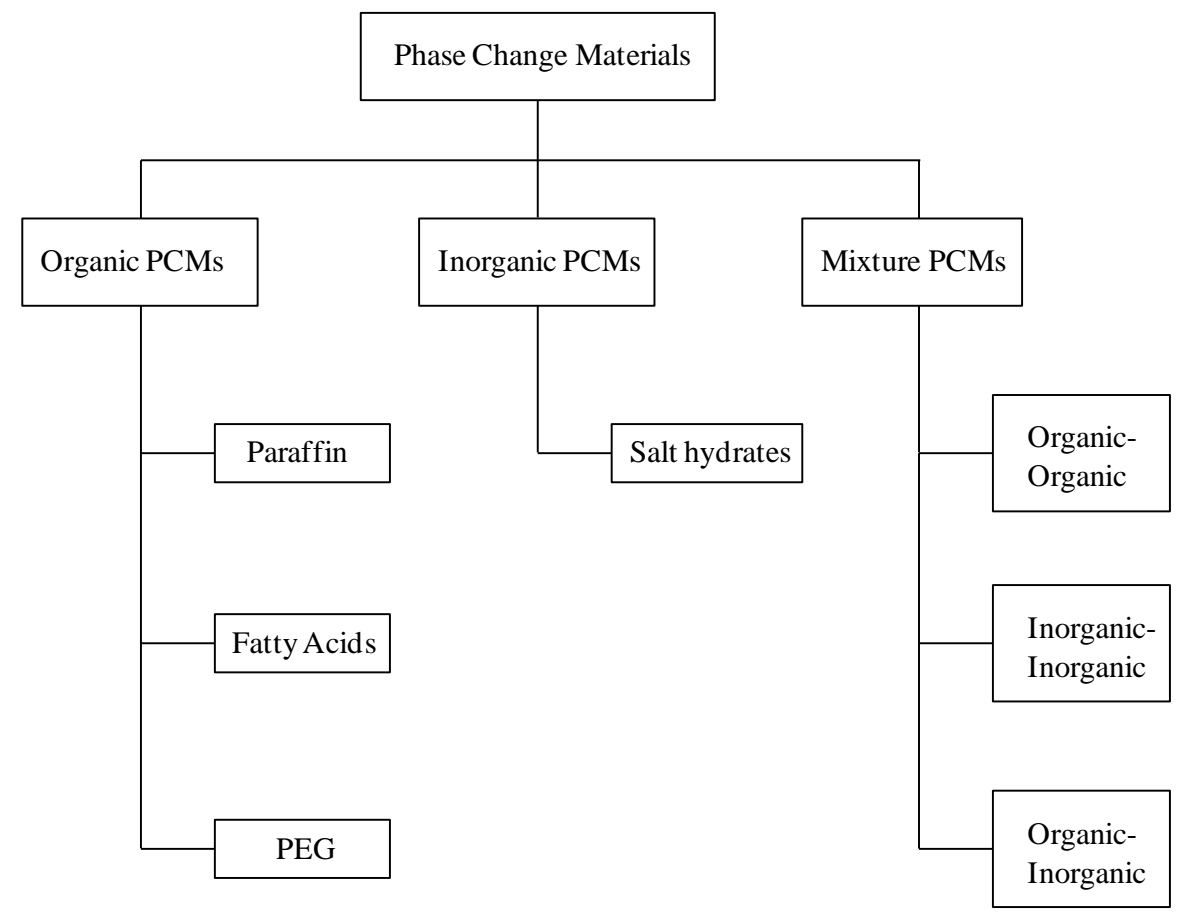

Fig.1 Classification of PCMs
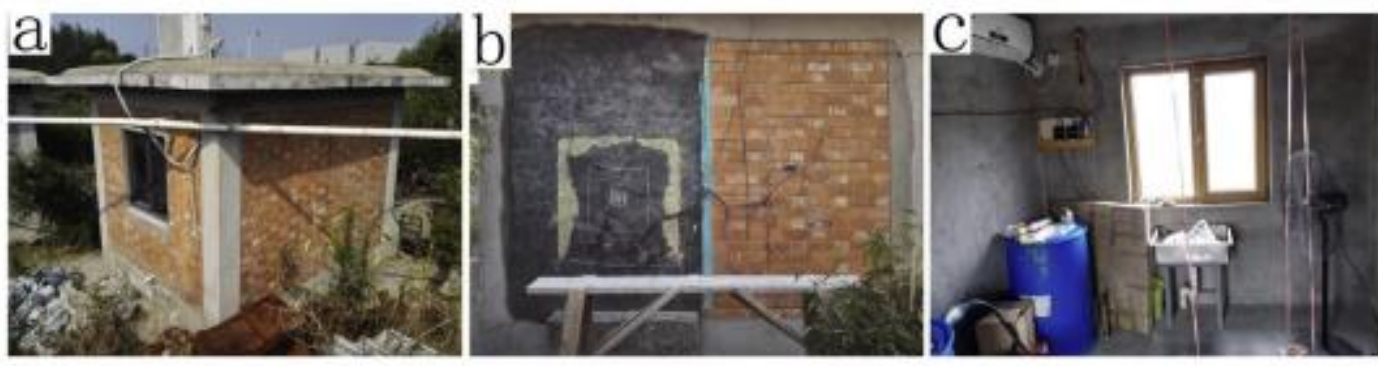

Fig. 2 Appearance of the tested room: (a) south view; (b) tested walls; (c) indoor appearance [82].

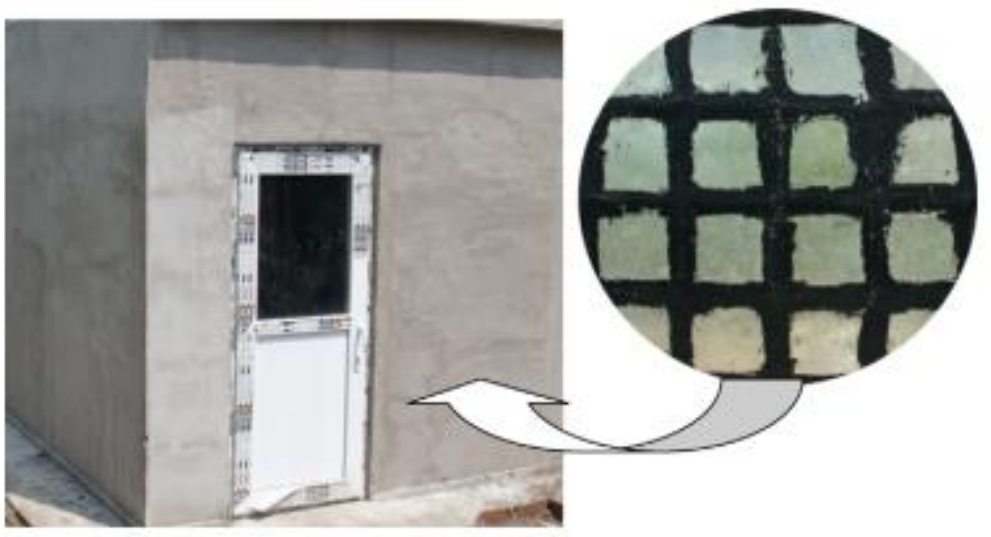

Fig.3 Demonstration of test rooms [84]. 

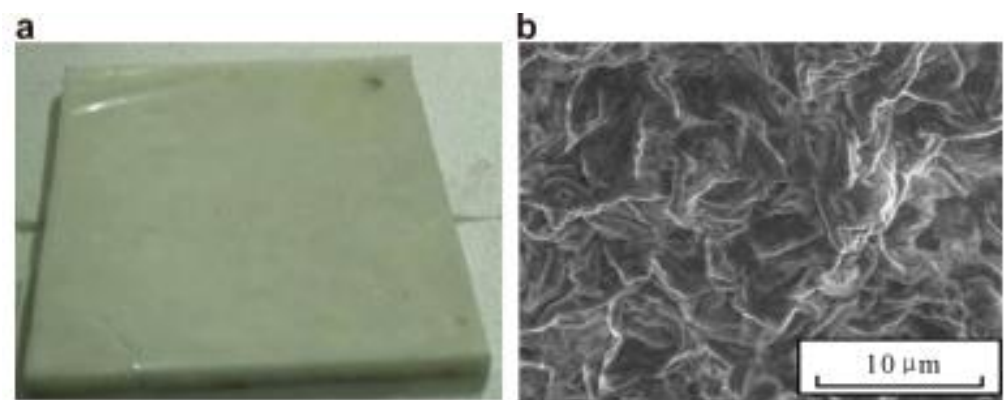

Fig.4 The photos of the shape-stabilized PCM: (a) photo of the PCM plate and (b) electronic microscopic picture by scanning electric microscope (SEM) [91-93].

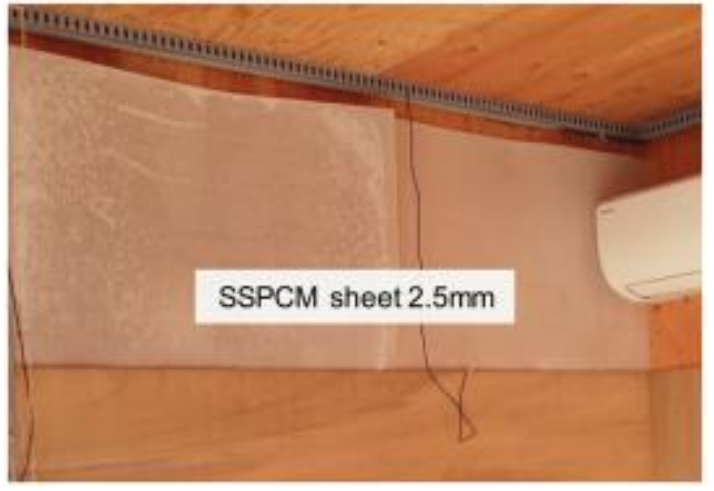

Fig.5 SSPCM sheet installation [97, 98].

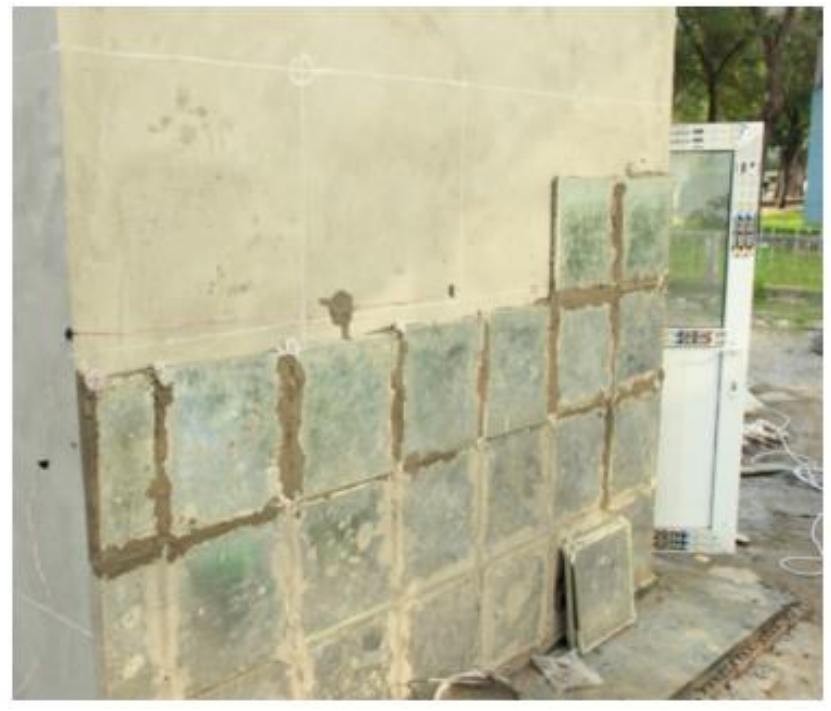

Fig.6 Demonstration of PCM panels installed for the PCMOW [99]. 


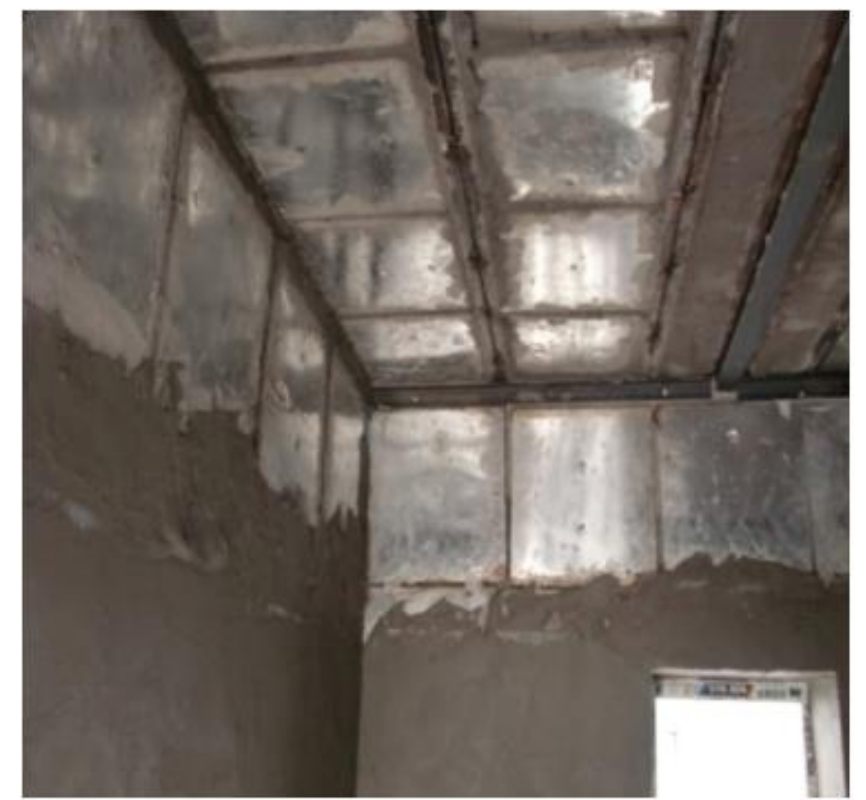

Fig.7 Demonstration of PCM panels installed for the PCMIW [99].

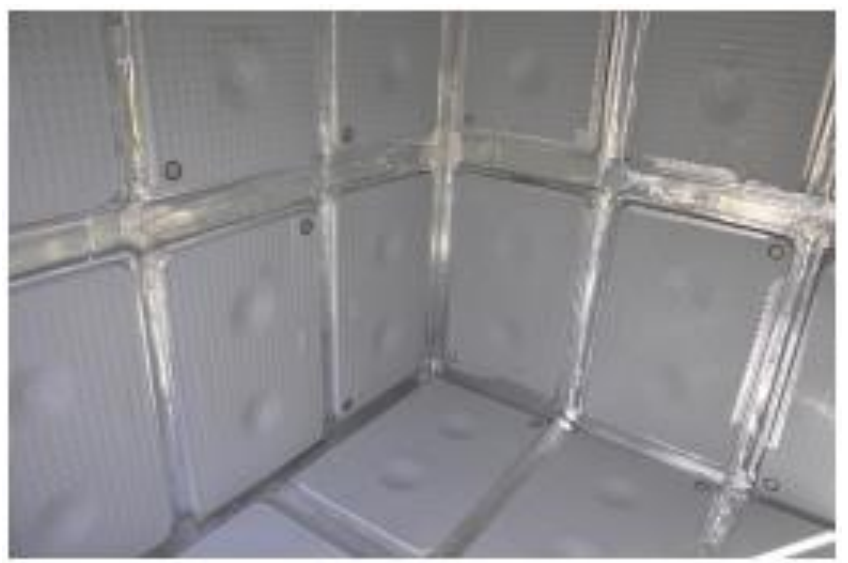

Fig.8 Appearance of SP29 and RT18 [100]. 

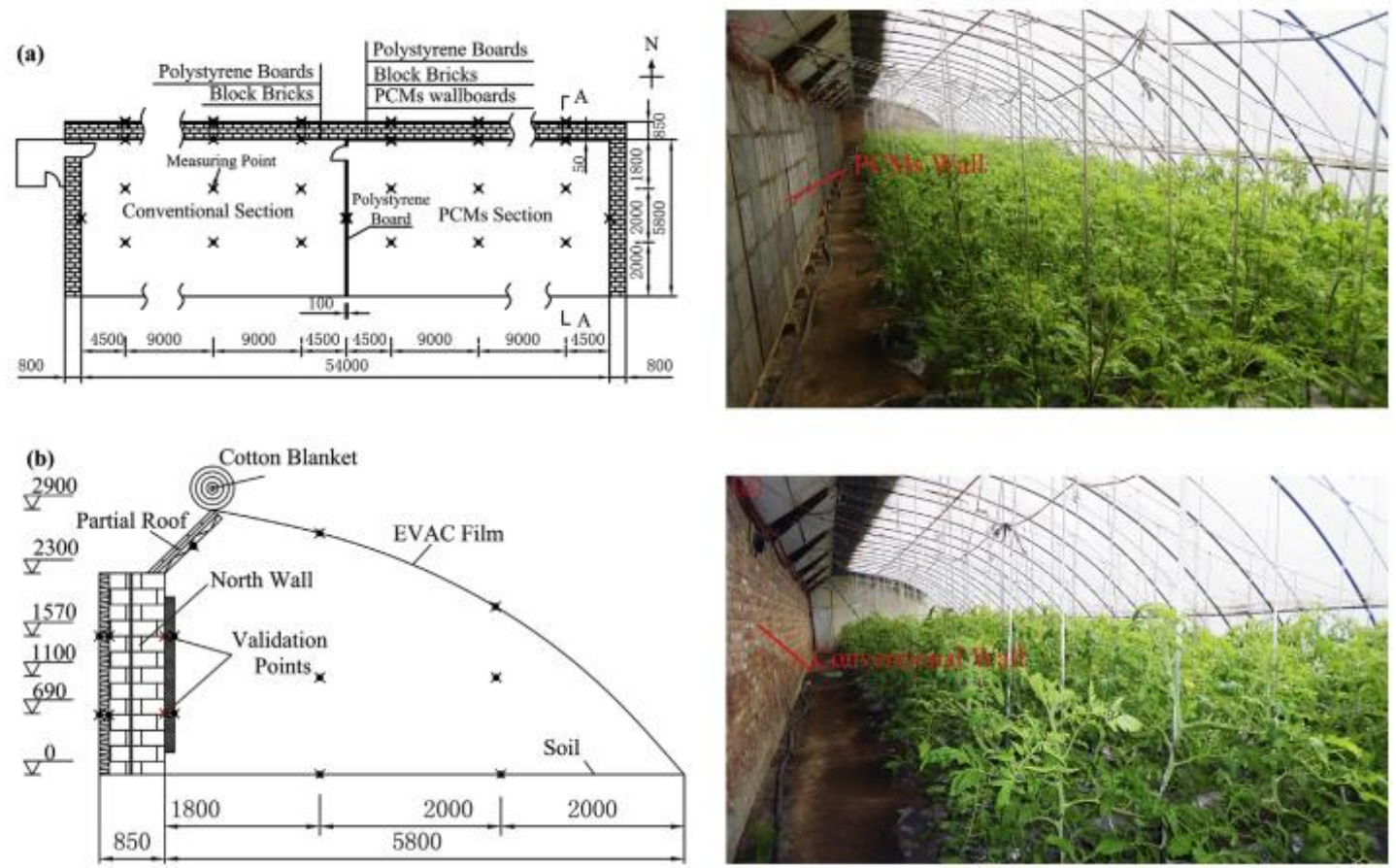

Fig.9 Schematic diagrams of the investigated greenhouse: (a) building layout, (b) A-A profile map, (c) section with PCMs, and (d) section without PCMs [103].

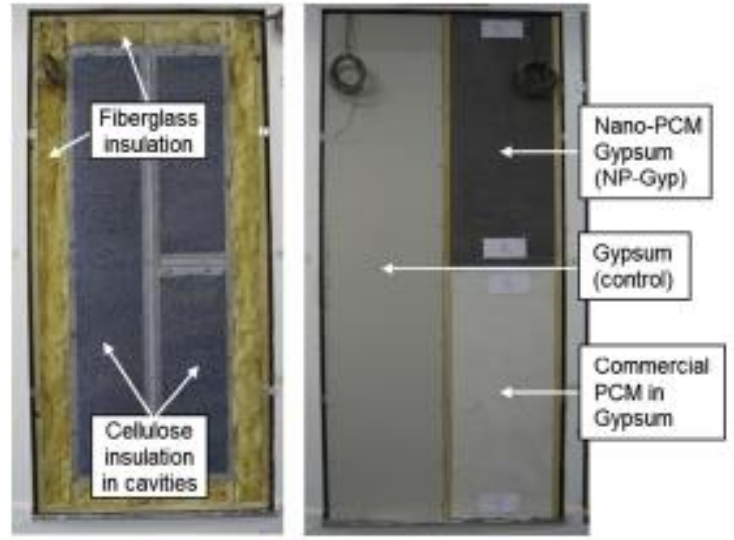

Fig.10 Test wall with the PCM-enhanced wallboards [104].

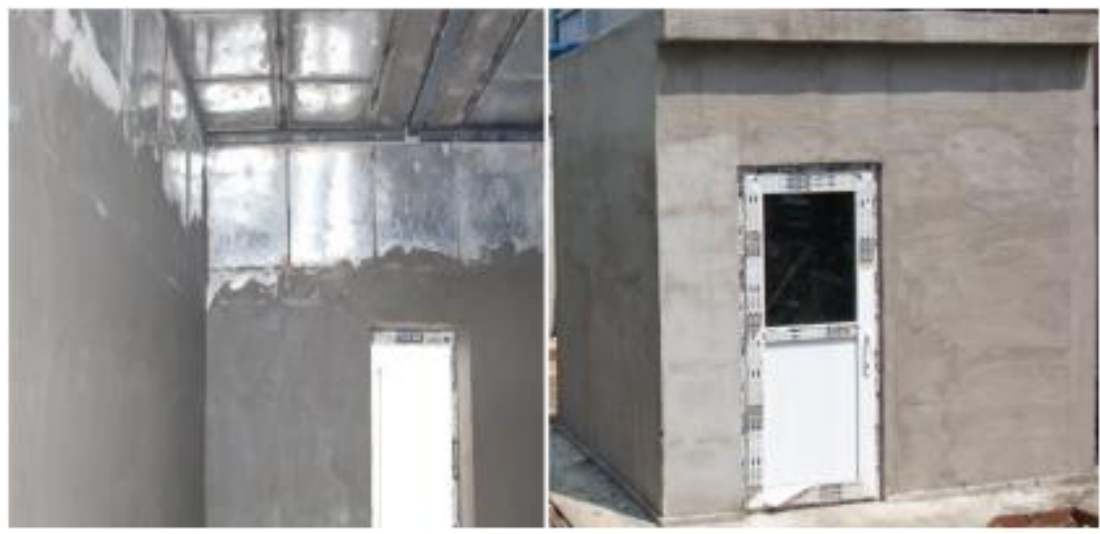

Fig.11 The construction diagram and the completion diagram [105]. 


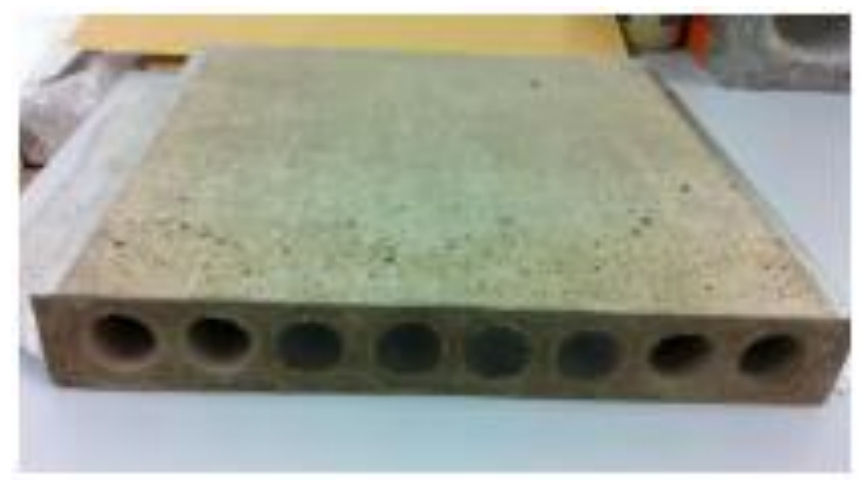

Fig.12 Image of floor panel [105].

\begin{tabular}{|c|}
\hline Surface layer \\
\hline PCM for cooling \\
\hline PCM for heating \\
\hline Cipe \\
\hline Concrete layer \\
\hline
\end{tabular}

Fig.13 The schematic of the double layer PCM floor [106].
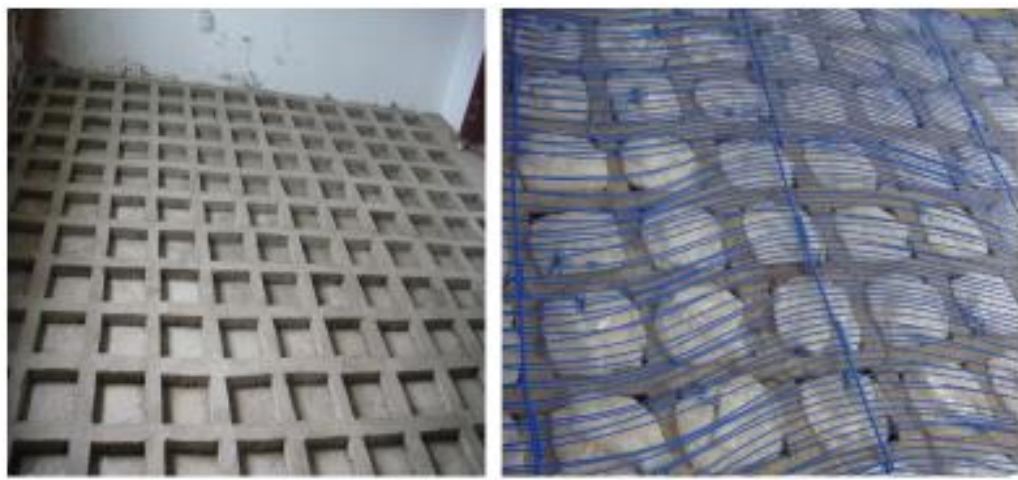

(a) Skeleton of PCM layer

(b) Image before smoothing the surface

Fig.14 The process of constructing the novel PCM floor [108]

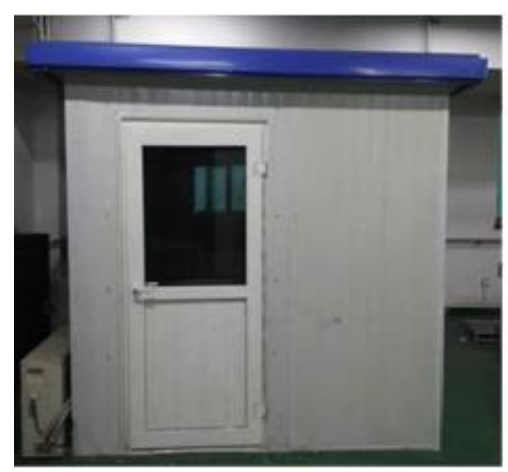

(a)

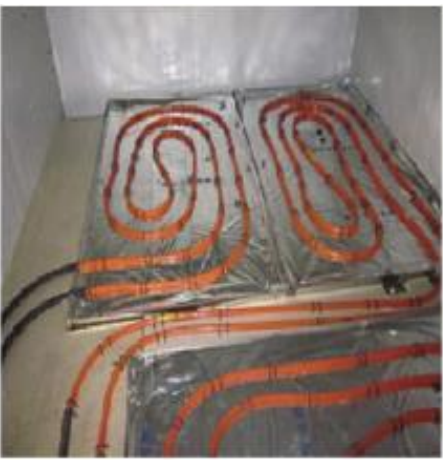

(b)

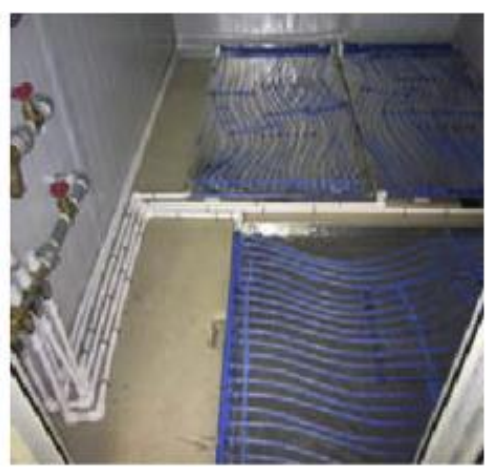

(c)

Fig. 15 The photos of test room and heating pipes. (a) test room; (b) PE coil; and (c) capillary mat [110]. 


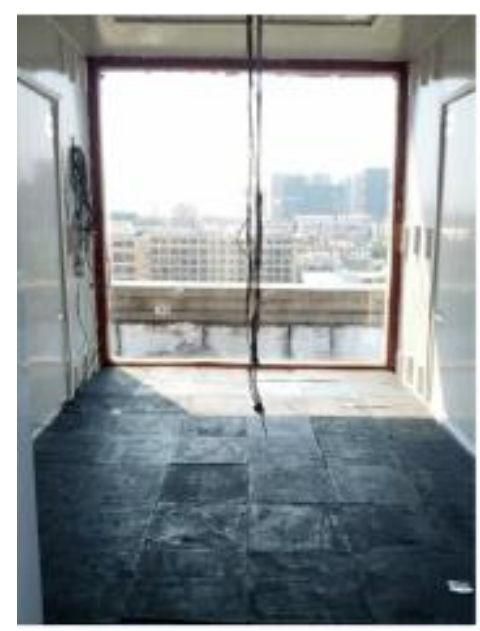

(a)

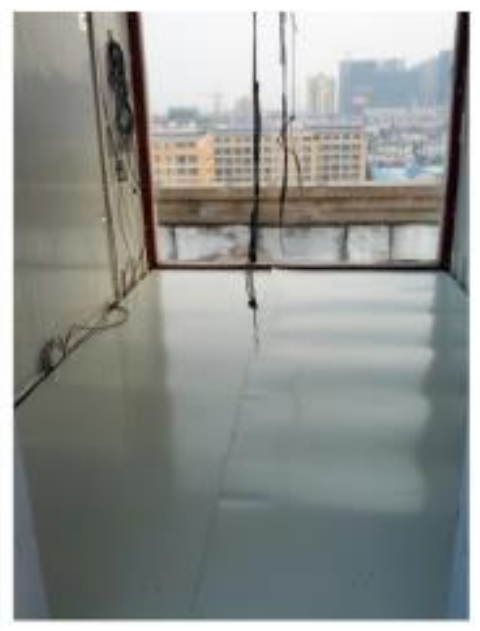

(b)

Fig.16 Phtos of the experiment unit (Room B) (a) Shows the view when the PCM plates were not covered with steels plates yet. (b) Shows the view when the preparatory work was completed. [111].

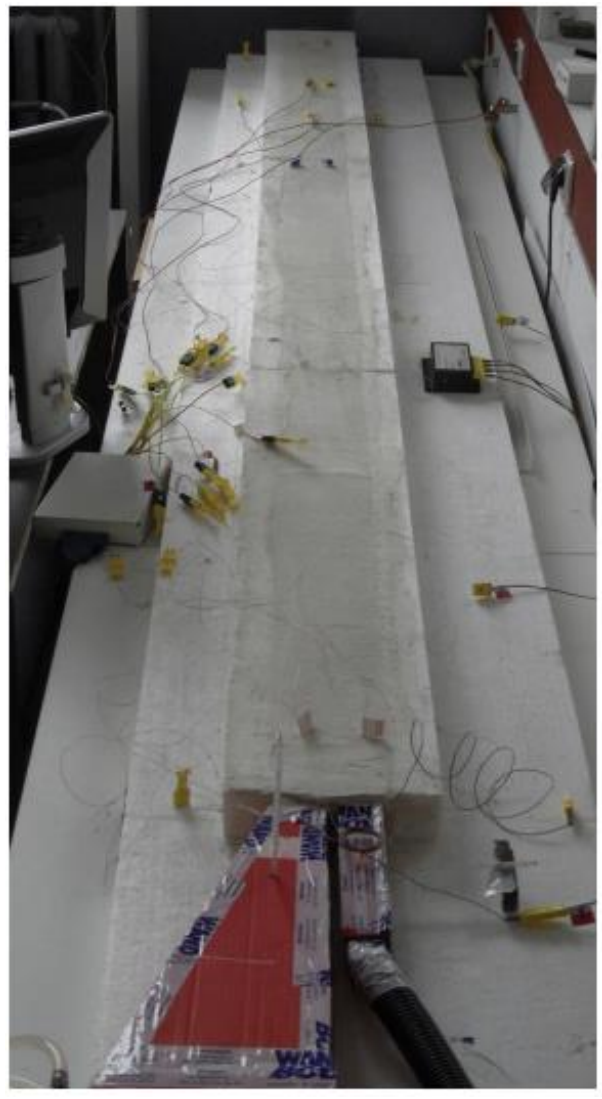

Fig.17 Photo of experimental set-up repetitive of a ceiling panel made of gypsumPCM composite [112]. 


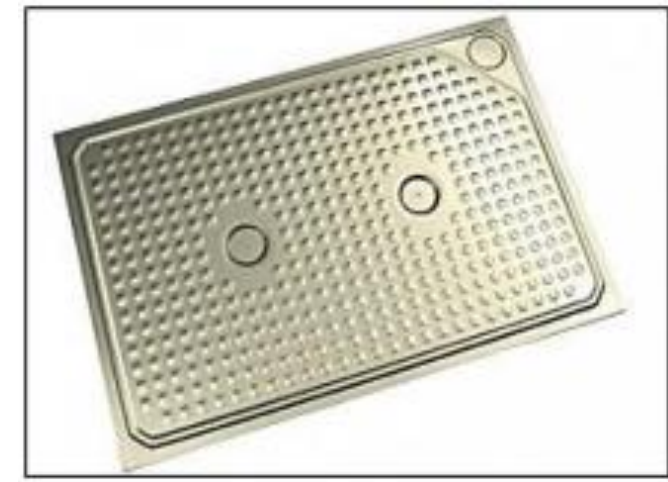

Fig.18 Rubitherm CSM PCM panel [114].

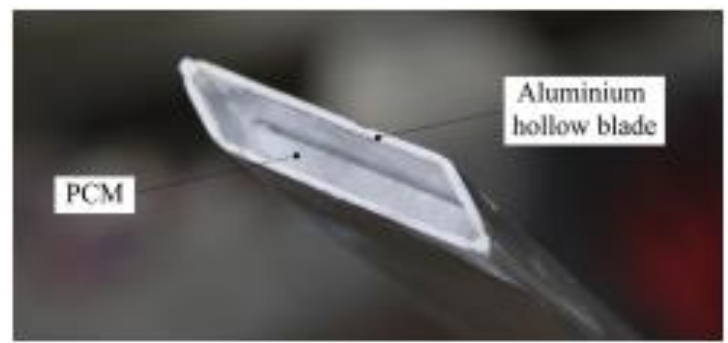

Fig.19 Window blade filled with PCM [117].
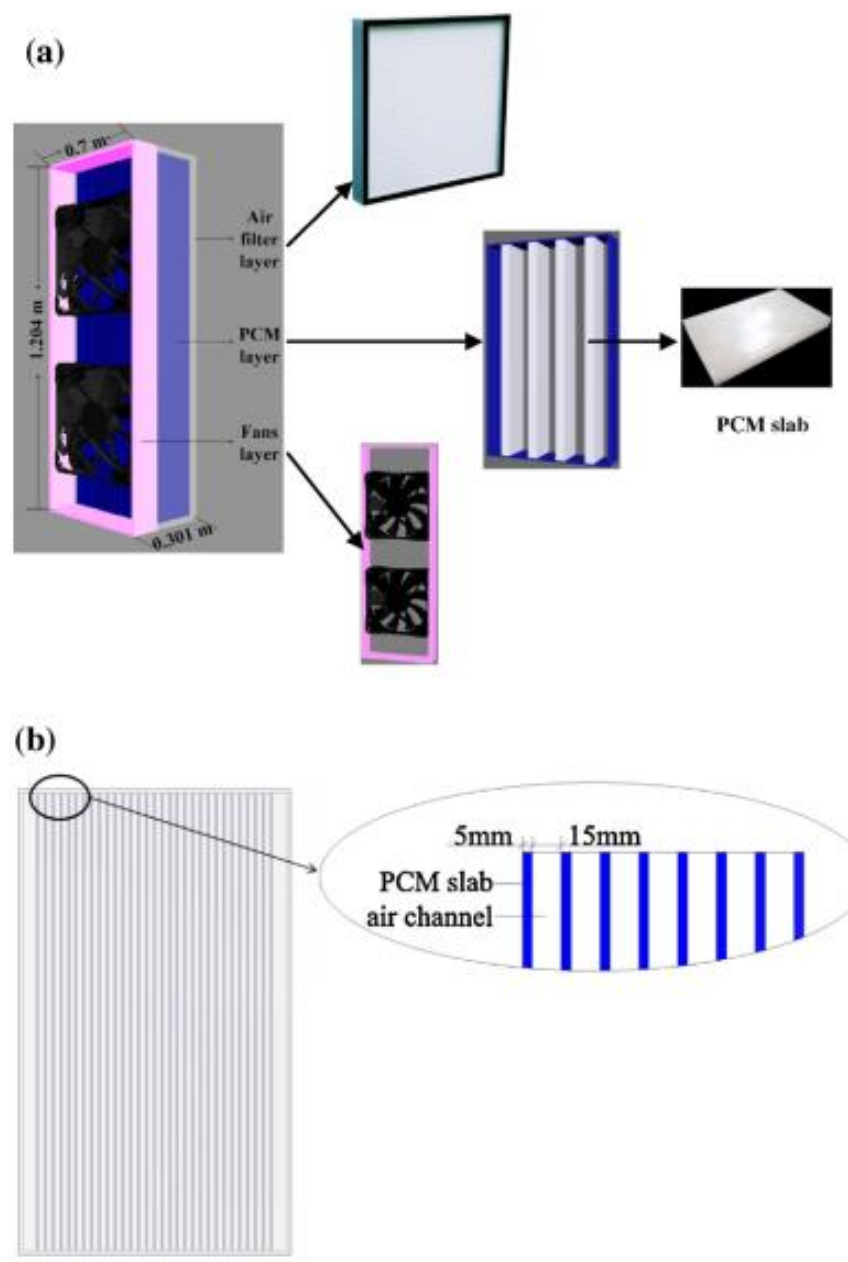

Fig.20 Cooling unit configuration: (a) perspective view of the cooling unit; (b) PCM layer [119]. 


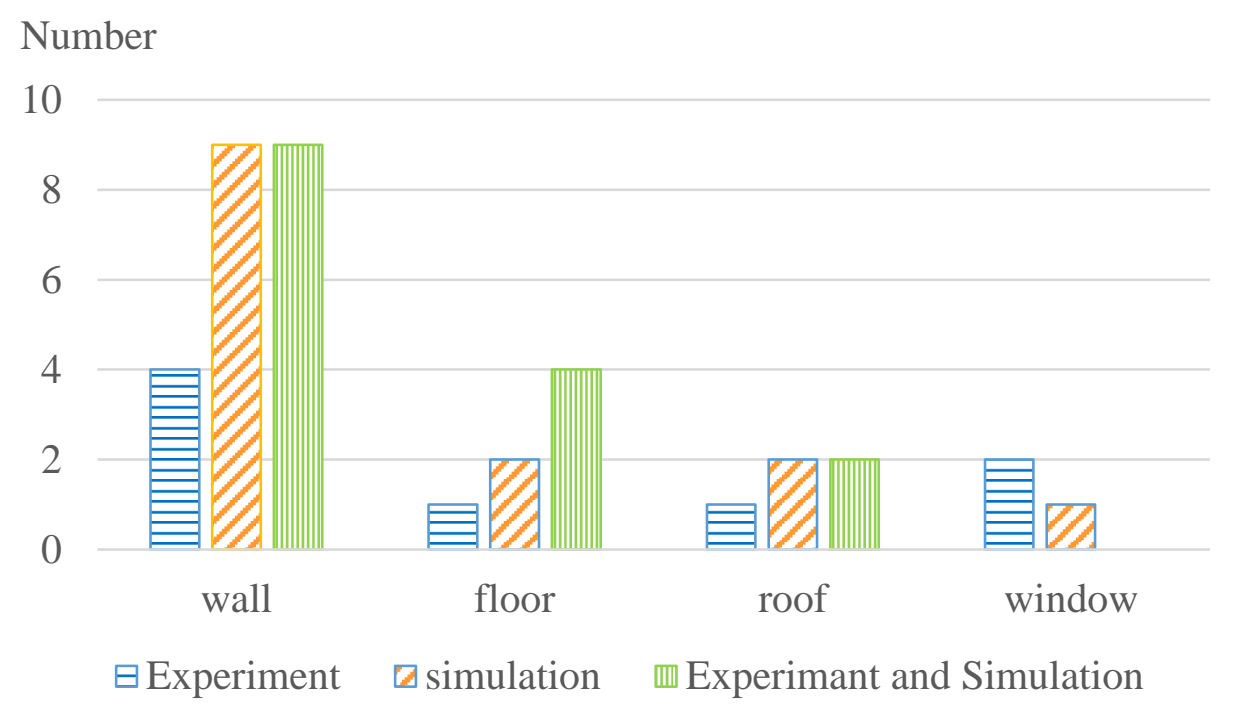

Fig.21 Number of reviewed papers from different types 
Table 1 Thermal properties of some organic SL-PCMs used in buildings

\begin{tabular}{|c|c|c|c|c|c|c|}
\hline PCMs & & $\mathrm{T}\left({ }^{\circ} \mathrm{C}\right)$ & $\Delta \mathrm{H}(\mathrm{J} / \mathrm{g})$ & $\rho(\mathrm{kg} / \mathrm{m} 3)$ & $\lambda(\mathrm{W} /(\mathrm{m} \cdot \mathrm{K}))$ & Ref. \\
\hline \multirow{8}{*}{ Paraffin } & Paraffin wax & 44 & 174.12 & $830(783)$ & 0.13 & [14] \\
\hline & RT-18 & $15-19$ & 134 & 756 & 0.2 & [15] \\
\hline & n-Heptadecane & 19 & 240 & & 0.21 & [16] \\
\hline & Paraffin & 25.72 & 106.2 & & & [17] \\
\hline & RT-25 & 26.6 & 232 & $785(\mathrm{~s}), 749(1)$ & $0.19(\mathrm{~s}), 0.18(1)$ & \multirow{2}{*}{ [18] } \\
\hline & Paraffin & 28.2 & 245 & $814(\mathrm{~s}), 775(1)$ & $0.35(\mathrm{~s}), 0.149(\mathrm{l})$ & \\
\hline & Paraffin & 28.18 & 180.5 & & & [19] \\
\hline & n-octadecane & 28.12 & 236.09 & & & [20] \\
\hline \multirow{9}{*}{$\begin{array}{l}\text { Fatty } \\
\text { acids }\end{array}$} & Capric acid & 32 & 152.7 & $878(\mathrm{~s}), 878(\mathrm{~s})$ & $0.372(\mathrm{~S}), 0.141(1)$ & [21] \\
\hline & Capric acid & & & & & \\
\hline & lauric acid & 43.05 & 172.3 & & & [22] \\
\hline & stearic acid & 54.29 & 188.28 & & & [23] \\
\hline & $\begin{array}{l}\text { Capric- lauric } \\
\text { acid }\end{array}$ & 19.09 & 141.5 & & & [24] \\
\hline & $\begin{array}{l}\text { lauric-myristic- } \\
\text { stearic acid }\end{array}$ & 29.29 & 140.9 & & & [25] \\
\hline & Lauric- & & & & & \\
\hline & palmitic-stearic & 32.1 & 151.6 & & & [26] \\
\hline & acid & & & & & \\
\hline \multirow{2}{*}{ PEG } & PEG800 & 25.39 & 133.6 & & & [27] \\
\hline & PEG4000 & 61.55 & 181.9 & & & [28] \\
\hline
\end{tabular}


Table 2 Thermal properties of some inorganic SL-PCMs used in buildings

\begin{tabular}{llllll}
\hline PCMs & $\mathrm{T}\left({ }^{\circ} \mathrm{C}\right)$ & $\Delta \mathrm{H}(\mathrm{J} / \mathrm{g})$ & $\rho(\mathrm{kg} / \mathrm{m} 3)$ & $\lambda(\mathrm{W} /(\mathrm{m} \cdot \mathrm{K}))$ & Ref. \\
\hline Hydrated salt & 29 & 175 & 1490 & 1.0 & {$[29]$} \\
$\mathrm{CaCl}_{2} \cdot 6 \mathrm{H}_{2} \mathrm{O}$ & 29 & 187.49 & $1800(\mathrm{~s}), 560(\mathrm{l})$ & $1.09(\mathrm{~s}), 0.54(\mathrm{l})$ & {$[30]$} \\
Hydrated salt & $25-34$ & 140 & & & {$[31]$} \\
$\mathrm{Na}_{2} \mathrm{SO}_{4} \cdot 10 \mathrm{H}_{2} \mathrm{O}-$ & & & & \\
$\mathrm{Na}_{2} \mathrm{HPO}_{4} \cdot 12 \mathrm{H}_{2} \mathrm{O}$ & 32.52 & 226.9 & & \\
$\mathrm{Na}_{2} \mathrm{CO}_{4} \cdot 10 \mathrm{H}_{2} \mathrm{O}-$ & & & & \\
$\mathrm{Na}_{2} \mathrm{HPO}_{4} \cdot 12 \mathrm{H}_{2} \mathrm{O}$ & & & & \\
\hline
\end{tabular}

T: Phase change Temperature, $\Delta H$ : Phase change latent heat, $\rho$ : Density, $\lambda$ : Thermal conductivity

Table 3 Properties of some mciroencapsulated PCMs used in buildings

\begin{tabular}{lcccc}
\hline & & & encapsulation efficiency & \\
Microencapsulated PCMs & $\mathrm{T}\left({ }^{\circ} \mathrm{C}\right)$ & $\Delta \mathrm{H}(\mathrm{J} / \mathrm{g})$ & Ref. & \\
\hline n-octadecane/ St-MMA & 29.5 & 107.9 & 45.1 & {$[39]$} \\
n-heptadecane/starch & 22.18 & 187.27 & 78.27 & {$[40]$} \\
Octadecane/silica & 28.32 & 227.66 & 95.1 & {$[41]$} \\
alkane mixture /methyl & & & & {$[42]$} \\
triethoxysilane & 27.2 & 94.4 & 63.4 & \\
n-eicosane/PMMA & 35.2 & 84.2 & & {$[43]$} \\
RT21/Polyurea & 27.5 & 92.5 & 44.5 & {$[44]$} \\
\hline
\end{tabular}


Table 4. Thermal properties of the porous material-based form-stable composite PCMs

\begin{tabular}{|c|c|c|c|c|c|c|}
\hline \multirow{3}{*}{ Form-stable PCMs } & \multirow{3}{*}{$\begin{array}{l}\text { Mass ratio } \\
\text { of PCM } \\
\text { (wt.\%) }\end{array}$} & \multicolumn{2}{|c|}{ Melting } & \multicolumn{2}{|c|}{ Freezing } & \multirow{3}{*}{ Ref } \\
\hline & & Temperature & Latent & Temperature & Latent & \\
\hline & & $\left({ }^{\circ} \mathrm{C}\right)$ & heat $(\mathrm{J} / \mathrm{g})$ & $\left({ }^{\circ} \mathrm{C}\right)$ & $(\mathrm{J} / \mathrm{g})$ & \\
\hline paraffin/EG & 85.6 & 48.93 & 161.45 & - & - & {$[70]$} \\
\hline MA-PA-SA/EG & 92.8 & 41.64 & 153.5 & 42.99 & 151.4 & [71] \\
\hline PA-SA/EG & 92.8 & 53.89 & 166.27 & 54.23 & 166.13 & {$[72]$} \\
\hline C-L-O acid/EG & 97.2 & 19.15 & 114.65 & 11.78 & 116.56 & {$[73]$} \\
\hline Tetradecanol/EG & 93 & 35.35 & 202.6 & 34.93 & 201.2 & {$[74]$} \\
\hline OD/WEPG & 70 & 29.6 & 159.9 & 25.0 & 160.7 & {$[75]$} \\
\hline Hydrated salts /EG & 87 & 32.05 & 172.3 & 17.11 & 140.8 & {$[76]$} \\
\hline $\mathrm{CaCl}_{2} \cdot 6 \mathrm{H}_{2} \mathrm{O} / \mathrm{EG}$ & - & 27.11 & 118.7 & 21.67 & 115.7 & {$[77]$} \\
\hline Paraffiin/Diatomite & 60 & 36.55 & 53.15 & 40.04 & 58.83 & {$[78]$} \\
\hline $\mathrm{CA} / \mathrm{EP}$ & 55 & 31.8 & 98.1 & 90.6 & 151.4 & [79] \\
\hline LA/EP & 60 & 44.13 & 93.36 & 40.97 & 94.87 & {$[80]$} \\
\hline LA/Vermiculite & 70 & 41.89 & 126.8 & 39.89 & 125.6 & [81] \\
\hline
\end{tabular}

